\title{
Platelet Signaling and Disease: Targeted Therapy for Thrombosis and Other Related Diseases
}

\author{
Jennifer Yeung, Wenjie Li, and Michael Holinstat \\ Departments of Pharmacology (J.Y., W.L., M.H.) and Internal Medicine, Division of Cardiovascular Medicine (M.H.), University of \\ Michigan, Ann Arbor, Michigan
}

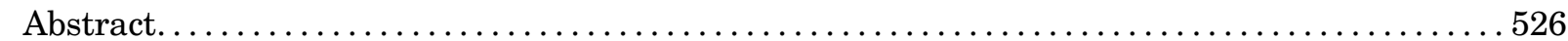

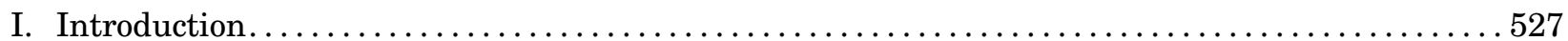

II. General Function of Platelets . . . . . . . . . . . . . . . . . . . . . . . . . . . . . . . . . . . . . 527

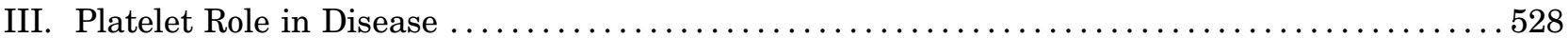

A. The Role of Platelets in Arterial Thrombosis . . . . . . . . . . . . . . . . . . . . . . . 529

B. The Role of Platelets in Venous Thrombosis ............................. 530

C. The Role of Platelets in Immune Responses ............................ 530

D. Platelets in Cancer Metastasis ........................................ 531

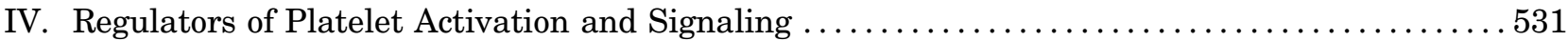

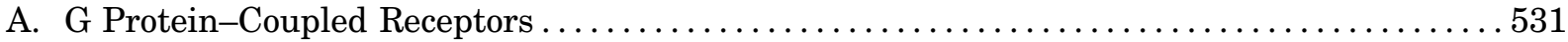

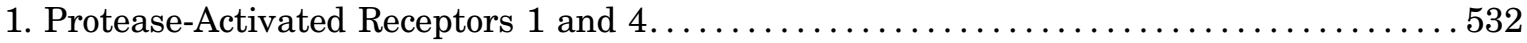

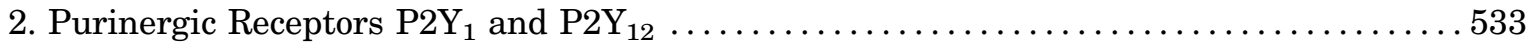

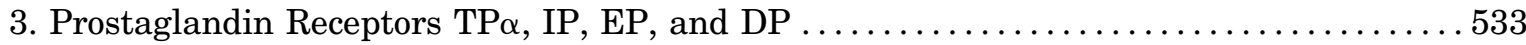

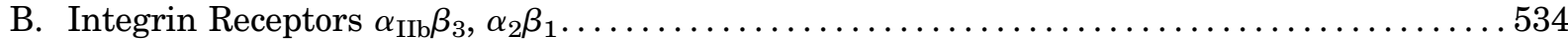

C. Immunoreceptor Tyrosine-Based Activation Motif Receptors ...................... 535

D. Enzymes Targeted for Regulation of Platelet Function........................ 535

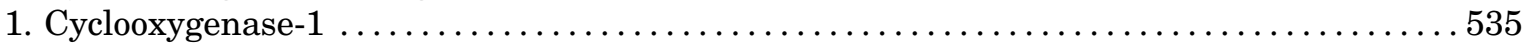

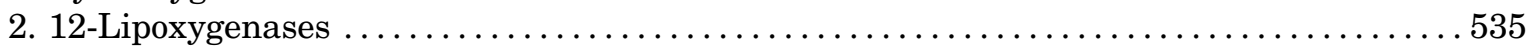

3. Cyclic Nucleotide Phosphodiesterases................................ 536

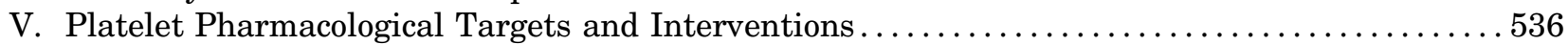

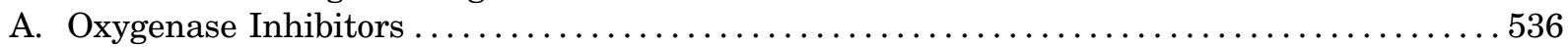

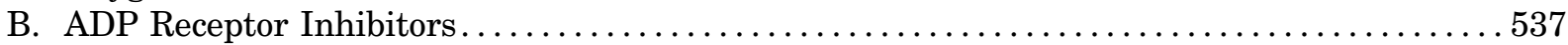

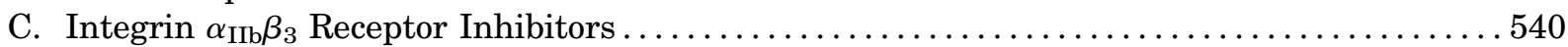

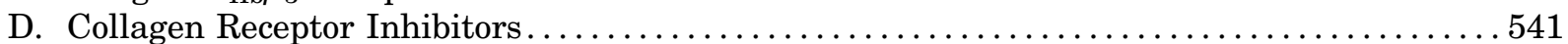

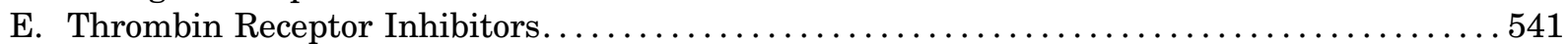

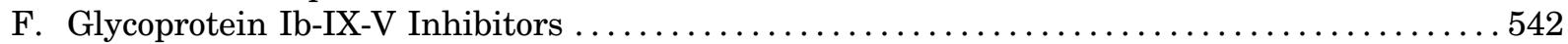

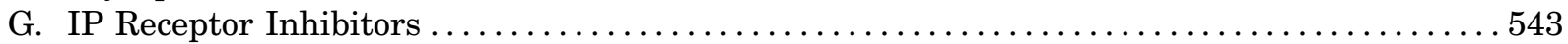

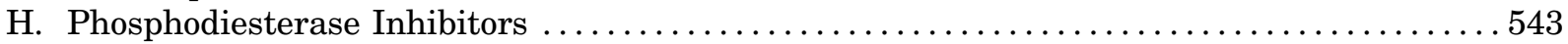

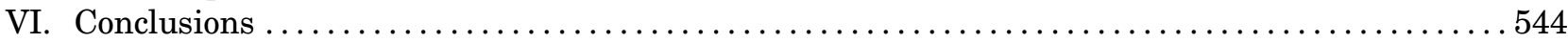

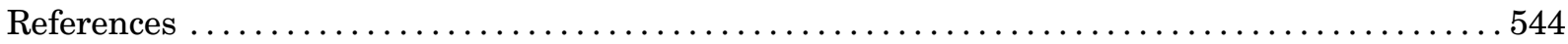

\begin{abstract}
Platelets are essential for clotting in the blood and maintenance of normal hemostasis. Under pathologic conditions such as atherosclerosis, vascular injury often results in hyperactive platelet activation, resulting in occlusive thrombus formation, myocardial infarction, and stroke. Recent work in the field has elucidated a number of platelet functions unique from

that of maintaining hemostasis, including regulation of tumor growth and metastasis, inflammation, infection, and immune response. Traditional therapeutic targets for inhibiting platelet activation have primarily been limited to cyclooxygenase-1, integrin $\alpha_{I I b} \beta_{3}$, and the $\mathrm{P} \mathrm{Y}_{12}$ receptor. Recently identified signaling pathways regulating platelet function have made it possible to
\end{abstract}

This work was supported by National Institutes of Health [Grants HL114405 (to M.H.), GM105671 (to M.H.), and HL129481 (to J.Y.)]. The content is solely the responsibility of the authors and does not necessarily represent the official views of the National Institutes of Health.

Address correspondence to: Dr. Michael Holinstat, Department of Pharmacology, University of Michigan, 1150 West Medical Center Drive, Room 2220D MSRB III, Ann Arbor, MI 48109. E-mail: mholinst@umich.edu

https://doi.org/10.1124/pr.117.014530. 
develop novel approaches for pharmacological intervention in the blood to limit platelet reactivity. In this review, we cover the newly discovered roles for platelets as well as their role in hemostasis and thrombosis. These new roles for platelets lend importance to the development of new therapies targeted to the platelet. Additionally, we highlight the promising receptor and enzymatic targets that may further decrease platelet activation and help to address the myriad of pathologic conditions now known to involve platelets without significant effects on hemostasis.

\section{Introduction}

Platelets are anucleate cells produced by megakaryocytes in the bone marrow and lungs (Weyrich and Zimmerman, 2013; Lefrançais et al., 2017) existing in the vessel for 5-10 days before they are removed from circulation by the spleen (Kaplan and Saba, 1978; Kuter, 1996). Their function in the body has predominantly been linked to maintaining normal flow in the blood vessel through a process known as hemostasis. When the vessel integrity is challenged, however, either through vessel injury, atherosclerotic plaque rupture, or chronic inflammatory conditions, platelets respond by clotting to form a thrombus at the site of injury. In addition to normal hemostasis, platelet activation often results in the formation of an occlusive thrombus leading to myocardial infarction and stroke. Due to the high turnover of the platelet in the body and its essential role in hemostasis and thrombosis, the platelet has long been a primary target for therapeutic intervention for the prevention of occlusive thrombotic events. This review is focused on delineating our current understanding of the roles that platelets play in both physiologic and pathophysiological conditions, the various potential drug targets expressed in the platelet or on its surface, and how classic and newly developed therapeutics have taken advantage of these targets to limit platelet activation in a number of pathophysiological conditions.

\section{General Function of Platelets}

Platelets are thought to be the primary mediators of hemostasis and thrombosis (Semple and Freedman, 2010). Under physiologic conditions, platelets circulate in the blood to maintain the blood constituents within the vessel (Jackson, 2011; Holinstat, 2017; Tomaiuolo et al., 2017) (Fig. 1). Due to the biologic and physical properties of the blood, including the numerous blood cells and plasma (white blood cells, red blood cells, platelets, plasma constituents) and the shear force inside the blood vessel, platelets are physically excluded from the central flow of the vessel and as a result are primarily found near the vessel wall. The location of platelets in the vessel due to this physical constraint enables the platelets to play a principal role in the quick hemostatic response following a vascular injury (Holinstat, 2017). When a vascular insult or injury occurs, platelets initially tether to the subendothelial extracellular matrix (ECM) through multiple receptors, including the collagen receptors $\alpha_{2} \beta_{1}$ and glycoprotein (GP)VI and von Willebrand factor (vWF) receptor glycoprotein receptor Ib-V-IX (Holinstat, 2017). Following firm adhesion to the subendothelial ECM, platelets undergo spreading, activation, and eventual aggregation to form a thrombus. Activated platelets also release granules or signals to aid in the recruitment and activation of nearby platelets to the localized thrombus.

Secondary activation via granule secretion and oxygenase catalysis from cyclooxygenase (COX)-1 and 12-lipoxygenase (LOX) is mediated through autocrine positive feedback on the platelet and paracrine signaling that stimulates circulating or loosely bound platelets to integrate into the existing clot to form an irreversible platelet plug at the site of injury. Although the platelet contains several types of granules that play unique roles in regulating platelet activity [dense $(\delta), \alpha$, and lysosomal], it is the dense granule that releases small molecules such as ATP, ADP, epinephrine, and serotonin, which play a predominant role in granuledependent paracrine activation of the surrounding platelets in the blood. The most highly investigated small molecule released from the dense granule is ADP, which further signals through the platelet purinergic receptors $\mathrm{P}_{2} \mathrm{Y}_{1}$ and $\mathrm{P} 2 \mathrm{Y}_{12}$, and it is this pathway that is targeted clinically for prevention of occlusive thrombosis. Similar to granule secretion, following platelet activation, the bioactive lipid products of free fatty

\footnotetext{
ABBREVIATIONS: 12(S)-HETE, 12(S)-hydroxyeicosatetraenoic acid; AA, arachidonic acid; ACS, acute coronary syndrome; ASA, acetylsalicylic acid; BPS, beraprost sodium; CLEC-2, C-type lectin-like receptor 2; COX, cyclooxygenase; cPLA 2 , cytocolic phosholipase $\mathrm{A}_{2}$; CYP450, cytochrome P450; DAG, diacylglycerol; DGLA, dihomo- $\gamma$-linolenic acid; ECM, extracellular matrix; EHEC, enterohemorrhagic Escherichia coli; EPA, eicospentaenoic acid; Fc $\gamma$ R, Fc receptor $\gamma$-chain; FDA, Food and Drug Administration; GP, glycoprotein; GPCR, G protein-coupled receptor; GPI, glycosylphosphatidylinositol; HCMV, human cytomegalovirus; HIT, heparin-induced thrombocytopenia; HUS, hemolytic-uremic syndrome; $\mathrm{IP}_{3}$, inositol triphosphate; ITAM, immunoreceptor tyrosine-based activation motif; LAT, linker for activated T cells; LOX, lipoxygenase; LPS, lipolysaccharide; MI, myocardial infarction; MP, microparticle; NET, neutrophil extracellular trap; PAD, peripheral arterial disease; PAH, pulmonary arterial hypertension; PAR, protease-activated receptor; PCI, percutaneous coronary intervention; PDE, phosphodiesterase; PDPN, podoplanin; PF4, platelet factor 4; PG, prostaglandin; PI3K, phosphoinositide 3-kinase; PLC, phospholipase C; PUFA, polyunsaturated fatty acid; TIA, transient ischemic attack; TLR, Toll-like receptor; TTP, thrombotic thrombocytopenic purpura; $\mathrm{TxA}_{2}$, thromboxane $\mathrm{A}_{2}$; UA/NSTEMI, unstable angina/non-ST elevation myocardial infarction; VEGF, vascular endothelial growth factor; VTE, venous thromboembolism; vWF, von Willebrand factor.
} 

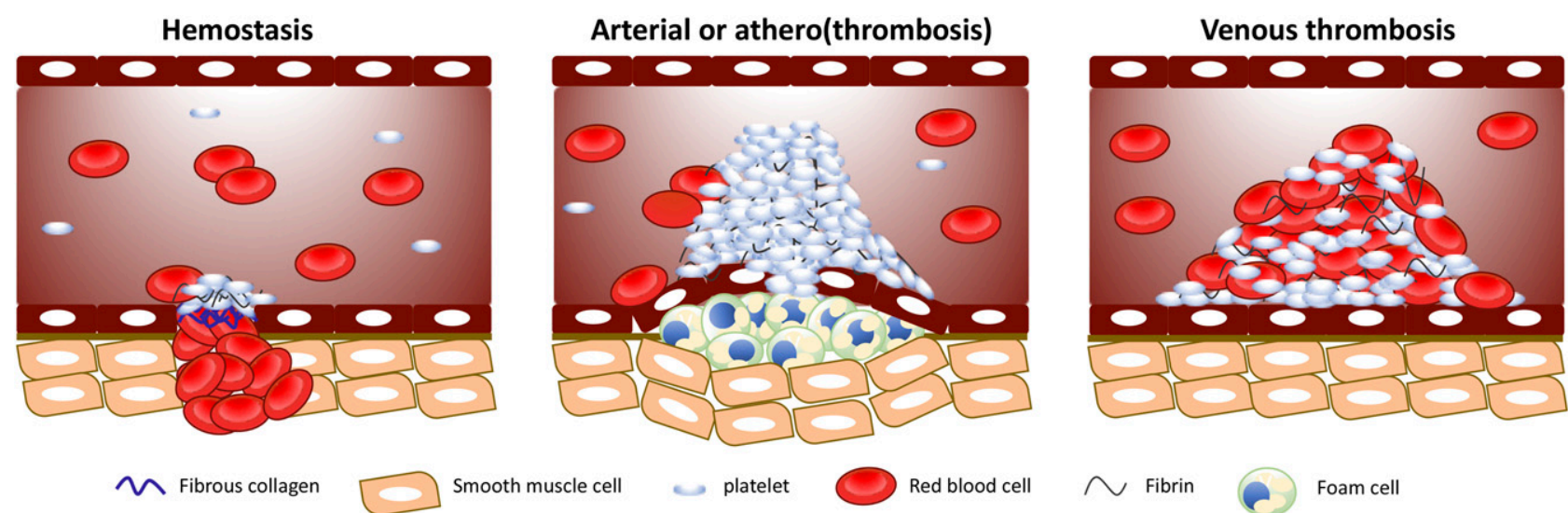

Fig. 1. The physiologic and pathophysiological roles of platelets. Platelets participate in hemostasis to prevent blood loss by forming a hemostatic plug following a vascular insult. In contrast, platelets can also partake in arterial and venous thrombosis, increasing the likelihood of vessel occlusion. The pathophysiological mechanisms of arterial and venous thrombus formation are distinct by which arterial thrombosis normally occurs following an atherosclerotic plaque rupture, leading to damaged endothelial cells, whereas, in venous thrombosis, the endothelial cells remained intact.

acids from arachidonic acid (AA), including prostaglandins $(\mathrm{PG}) \mathrm{E}_{2}$ and thromboxane $\mathrm{A}_{2}\left(\mathrm{TxA}_{2}\right)$, formed via COX-1 and eicosanoids [12(S)-hydroxyeicosatetraenoic acid (12(S)-HETE)], produced via 12-LOX, interact with their respective G protein-coupled receptors (GPCRs) to reinforce platelet activation (Holinstat, 2017). This complex process of platelet adhesion followed by aggregation and recruitment of platelets to the site of injury is best exemplified by recent studies showing a thrombus composed of an outer loose shell overlaying the densely packed inner core. P-selectin-positive platelets are localized to the inner core area of a thrombus at the site of injury and are tightly packed together in an irreversible clot, whereas the platelets located in the shell of the thrombus are more sensitive to the inhibition of positive feedback signaling through the thromboxane receptor $(\mathrm{TP} \alpha)$ and the $\mathrm{ADP}$ receptor $\left(\mathrm{P}_{2} \mathrm{Y}_{12}\right)$ (Stalker et al., 2013; Welsh et al., 2014, 2016).

Beyond the well-established role for platelet regulation of hemostasis and thrombosis, it has been proposed that platelets have distinctive roles in regulating and assisting immune responses and inflammatory reactions (von Hundelshausen and Weber, 2007). The adhesive molecule P-selectin that is highly expressed on the platelet surface following activation regulates the extent of interaction between activated platelets and P-selectin glycoprotein ligand-1-expressing immune cells (lymphocytes, neutrophils, and monocytes), leading to micro-aggregate formation and leukocyte rolling and arrest (Diacovo et al., 1996a,b). Other platelet surface receptors, including $\alpha_{\mathrm{IIb}} \beta_{3}$ (Oki et al., 2006), CD40 ligand (Prasad et al., 2003), intercellular adhesion molecule 2 (Diacovo et al., 1994), junctional adhesion molecules (Prota et al., 2003), and chemokine receptors (Murphy et al., 2000), have been proposed to link the immune system to platelets. Additionally, all nine Toll-like receptors (TLRs) were found to be expressed on platelets (Holinstat and Tourdot, 2015; Koupenova et al., 2015). These receptors are known to be involved in innate immunity against viral, bacterial infection, and even tumors, providing evidence that platelets are an integral component of the immune reporting system. To this end, platelets have previously been reported to exhibit autophagy in activation (Ouseph et al., 2015). Additionally, platelets are known to sample the blood environment and assist other immune cells by presenting foreign pathogens (Assinger, 2014; Holinstat, 2017; Koupenova et al., 2018). Hence, platelet whose function was once thought to be limited to maintaining the vessel integrity through regulation of hemostasis and thrombosis is now known to participate in a number of additional functions, including immunity and inflammation. As we continue to investigate the ever-expanding role of the platelet in circulation, it is likely that its role in the body will likewise expand to include regulation of tumor growth and metastasis and signaling distal tissue beds in the vascular tree through microparticle (MP) communication (Gastpar, 1977; Jurasz et al., 2004; Boilard et al., 2010; Italiano et al., 2010).

\section{Platelet Role in Disease}

The pathophysiological mechanisms underlying the formation of arterial and venous thrombi are distinct. Arterial clots are formed under high shear stress, typically after rupture of an atherosclerotic plaque or other damage to the blood vessel wall. They are deemed platelet-rich or white clots and are generally treated with antiplatelet drugs (see Platelet Pharmacological Targets and Interventions). In contrast, venous thromboses are largely fibrin-rich or red clots formed under low shear stress on the surface of largely intact endothelium, and anticoagulants are clinically used to treat patients with venous thromboembolism (VTE). There is accumulating evidence that whereas the venous thrombotic clot is a condition rich in red blood cells, platelets represent a major component in the 
development of VTE (Fig. 1) as well as their active participation in immune response to foreign substances, including drug, bacteria, and viruses (Fig. 2).

There is also a growing body of evidence that activated platelets contribute to other pathophysiological disease states, including arterial and venous thrombosis, heparininduced thrombocytopenia (HIT), cancer, and sickle cell disease (Italiano et al., 2010), through shedding of MPs or vesicular membrane fragments. Platelet MPs are highly heterogeneous in size, ranging from 0.05 to $1 \mu \mathrm{m}$, organelle content, and phosphatidylserine surface expression (Italiano et al., 2010; Boilard et al., 2015). Interestingly, several studies have shown platelet MPs can engulf as well as transfer their contents (proteins or nucleic acids) to nearby cells, most notably tumor cells (Best et al., 2015; Michael et al., 2017). Depending on the contents, platelet MPs can either suppress or enhance the metastatic capabilities of tumor cells (Dashevsky et al., 2009; Varon et al., 2012; Michael et al., 2017). Despite their apparent participation in these physiologic or pathophysiological processes, the fundamental aspects underlying their mechanisms remain largely unexplored. Currently, there are ongoing efforts to improve the methodologies in characterizing the diversity of MPs to aid in platelet-related disease biopsies or diagnosis. This section will detail the various pathophysiological conditions in which platelets play an important role and for which antiplatelet drugs are likely to represent a significant treatment option in the patient.

\section{A. The Role of Platelets in Arterial Thrombosis}

The pathogenesis of arterial thrombosis is complex and dynamic. Arterial thrombosis is initiated following endothelial damage from vascular injury or pathologic atherosclerotic plaque rupture under conditions of high shear rates (Fig. 1). Circulating platelets are rapidly decelerated and transiently interact with the damaged and exposed subendothelial connective tissue containing immobilized vWF bound to collagen (types I, III, and VI). vWF-collagen interacts with the platelet glycoprotein receptor Ib-V-IX complex, allowing platelets to translocate along the vessel wall and engage their receptors, GPVI and integrin $\alpha_{2} \beta_{1}$, with the subendothelial fibrillar collagen. This firm interaction also facilitates platelets to associate with fibronectin through its engagement with integrin $\alpha_{5} \beta_{1}$.

The engagement of platelet receptors with collagen also induces an inside-out cellular signaling cascade that leads to integrin $\alpha_{\mathrm{IIb}} \beta_{3}$ activation (Coller and Shattil, 2008; Shattil et al., 2010). This process involves intermediary proteins, talin and kindlin, which bind to the cytoplasmic domain of $\beta_{3}$ integrin to shift $\alpha_{\mathrm{IIb}} \beta_{3}$

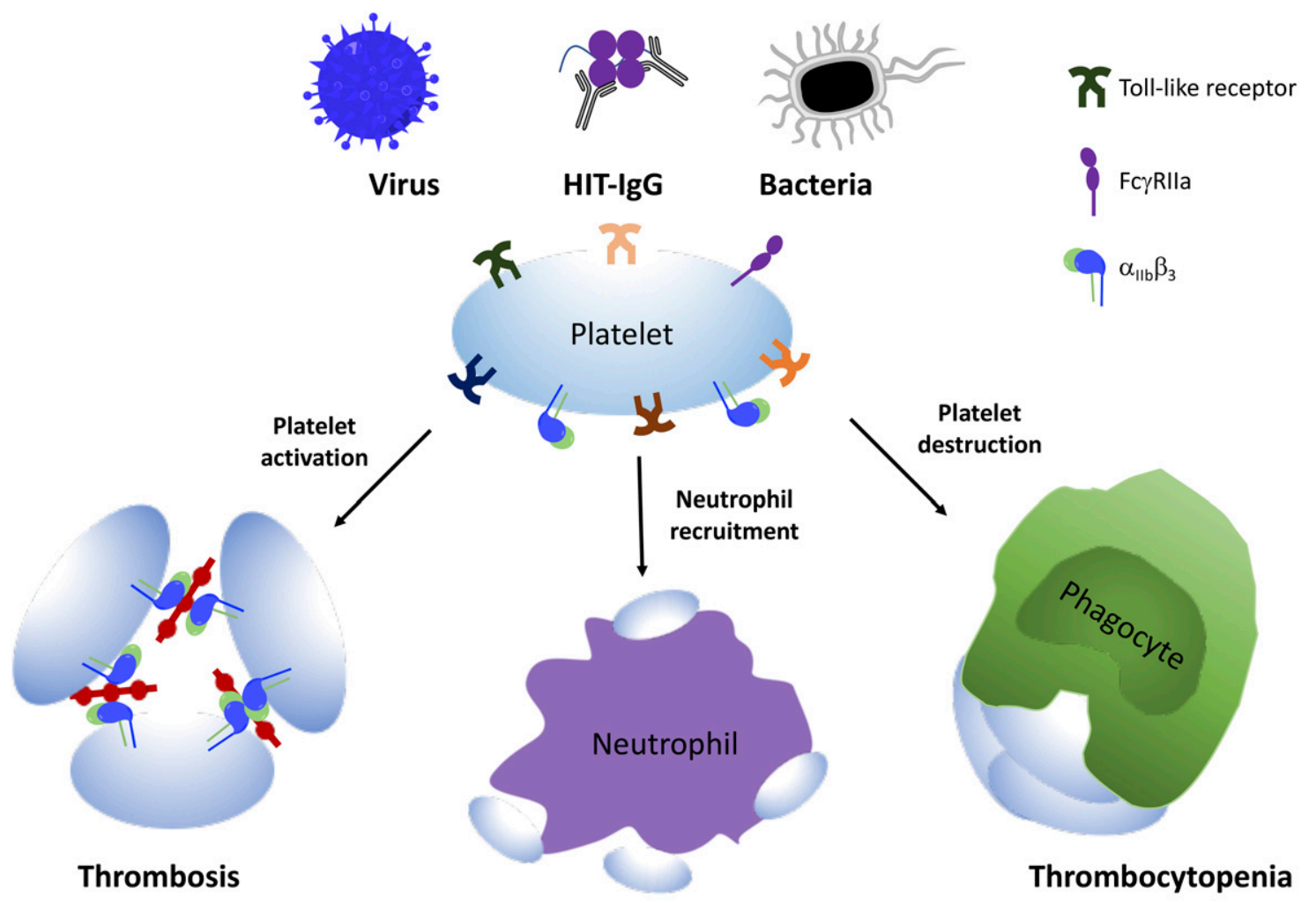

\section{Neutrophil-platelet aggregates}

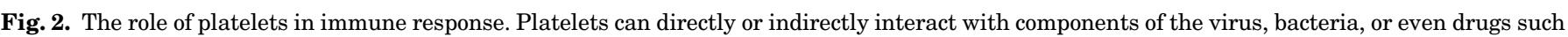

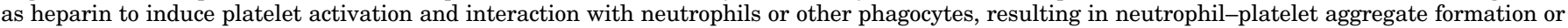
thrombocytopenia. 
from an inactive to active state (Tadokoro et al., 2003; Moser et al., 2008). Active $\alpha_{\mathrm{IIb}} \beta_{3}$ conformation increases its affinity for adhesive proteins, vWF, fibrinogen, fibrin, and fibronectin. These interactions are essential for the platelets to form stable aggregates with other activated platelets to promote thrombus growth.

Following firm adhesion and aggregate formation, platelets also release or locally generate soluble agonists, such as $\mathrm{ADP}, \mathrm{TxA}_{2}$, and thrombin, to mediate feed-forward autocrine and paracrine platelet activation via their respective GPCRs. The activation of GPCRs initiates a series of intracellular signaling events, including generation of second messengers [diacylglycerol (DAG) and inositol triphosphate $\left(\mathrm{IP}_{3}\right)$ ]. Eventually, the cascade of downstream signaling events culminates in the secretion of soluble factors, platelet spreading, and integrin activation. The secreted soluble agonists act on circulating platelets to be recruited and incorporated into a growing thrombus.

\section{B. The Role of Platelets in Venous Thrombosis}

VTE comprises deep vein thrombosis and pulmonary embolism. The underlying pathophysiology of venous thrombosis has predominantly been attributed to Virchow's Triad: hypercoagulability, alterations in blood flow (stasis and turbulence), and endothelial dysfunction (Mackman, 2012). Platelets have traditionally not been thought to be a major player of venous thrombosis; however, increasing experimental evidence has demonstrated an important platelet contribution to the pathophysiology of venous thrombosis (Montoro-García et al., 2016). Platelet membranes are thought to contribute approximately $95 \%$ of the MPs found in circulation. Elevated MPs have been extensively described in patients with VTE, especially in cancer patients (Chirinos et al., 2005; Ay et al., 2009; Tesselaar et al., 2009; Zwicker et al., 2009; Garcia Rodriguez et al., 2010; Manly et al., 2010). In an ectopic cancer model, mice treated with clopidogrel, a $\mathrm{P}_{2} \mathrm{Y}_{12}$ inhibitor, decreased tumor size and restored hemostasis by preventing the accumulation of cancer cell-derived MPs at the site of thrombosis (Mezouar et al., 2015). The in vivo use of antiplatelet drugs, clopidogrel and acetylsalicylic acid (ASA), in dogs, rat, rabbits, as well as the in vitro models, by which they reduced venous thrombus formation, has supported the role of platelets in the pathophysiology of venous thrombosis (Herbert et al., 1993; Bernat and Herbert, 1994; Savi et al., 1994, 2000; Imbault et al., 1996; Arroyo et al., 2001; Moore and Deschler, 2007; Wang et al., 2007). Deletion of the $\mathrm{P}_{2} \mathrm{Y}_{1}$ receptor, a purinergic receptor expressed in the platelet, also showed reduced venous thrombosis formation (Bird et al., 2012). Furthermore, the ASPIRE and WARFASA clinical trials have provided strong evidence that ASA after initial anticoagulation is ceased reduces the rate of recurrence of VTE in patients with a prior unprovoked VTE (Becattini et al., 2012; Brighton et al., 2012). In fact, aspirin was shown to reduce recurrent events by more than one-third without significantly increasing the risk of bleeding.

\section{The Role of Platelets in Immune Responses}

Extending beyond the classic roles of hemostasis and thrombosis, platelets are increasingly being recognized for their functions in immune-pathologic disorders in the blood, such as inflammation and non- or proinfectious immunologic functions (Sullam et al., 1988; Pampolina and McNicol, 2005; Fitzgerald et al., 2006b; Arman et al., 2014; Boilard et al., 2014). Although there is developing understanding on the mechanisms by which foreign substances initiate host immune response via platelet interactions, the role of platelets in immunity is complex. Depending on the type of foreign agent, platelet activation can be enhanced, leading to either prothrombotic events or dampened platelet response, resulting in bleeding complications. In this section, an overview of platelet overlap with the immune response following bacterial, viral, or drug exposure will be discussed briefly.

Human and murine platelets express all nine TLRs (Koupenova et al., 2018) in addition to $\mathrm{Fc} \gamma$ receptors that are used by the innate and adaptive immune cells (macrophages, neutrophils, and dendritic cells) (Shiraki et al., 2004) to induce platelet response that indirectly bridges communication between platelets and other myeloid progenitor cells. For instance, Gram-negative bacteria-derived endotoxin, lipolysaccharide (LPS), plays a fundamental role in sepsis through the activation of the TLR4 on neutrophils. Similarly, LPS induction of TLR4 on platelets can lead to platelet-neutrophil aggregate formation and subsequent neutrophil extracellular trap (NET) activation known as NETosis (Clark et al., 2007). NETosis is a dynamic process that may either have a beneficial effect for the host in isolating and preventing the spread of invading bacteria or detrimental outcome by which platelet-induced activation of neutrophils promotes injury to the host. Platelet TLR4 activation by LPS has also been shown to induce in vivo microvascular thrombosis in mice, resulting in thrombocytopenia (Zhang et al., 2009), as well as enhanced ex vivo platelet secretion and aggregation.

TLR4 also plays a role in hemolytic-uremic syndrome (HUS), characterized by nonimmune microangiopathic hemolytic anima, thrombocytopenia, and renal failure (Prohászka, 2008). Human platelets have been demonstrated to bind to the O157:H7 LPS serotype derived from enterohemorrhagic Escherichia coli (EHEC) through TLR4 (Ståhl et al., 2006). Such binding of LPS is shown in platelets from children with HUS after EHEC infection, but not in children who did not develop HUS after EHEC infection, suggesting that platelet-LPS interaction may contribute to thrombocytopenia during HUS. In addition, platelets from HUS patients show elevated platelet markers [P-selectin, platelet factor 4 (PF4)], MPs, and $\beta$-thromboglobulin (Appiani et al., 1982; Katayama et al., 1993; Galli et al., 1996). 
Besides TLR4, platelets can interact with various bacteria (Staphylococci family, Neisseria gonorrheae, Porphyromonas gingivalis, and Helicobacter pylori) (Fitzgerald et al., 2006a; Yeaman, 2010; HamzehCognasse et al., 2015) by using their Fc $\gamma$ RIIa (Fc fragment of IgG receptor IIa), complement receptors, or glycoprotein receptors. Following bacterial interaction, activated platelets enhance P-selectin expression to mediate its association with the $\mathrm{P}$-selectin receptor on neutrophils as well as secrete the antimicrobial peptide, $\beta$-defensin, to induce NET formation (Kraemer et al., 2011). Similar to HIT, a life-threatening disorder that is characterized by low platelet count and thromboembolic complications, circulating PF4 can also recognize Gramnegative bacteria, leading to the formation of PF4/ heparin-like epitopes. Exposed PF4/bacterial epitopes are recognized by autoantibodies, which in turn can bind to the platelet Fc $\gamma$ RIIa and induce platelet activation or destruction by opsonization mediated by neutrophils (Krauel et al., 2011, 2012).

Viruses also rely on the same family of receptors as the bacteria to mediate platelet-virus interaction. Human cytomegalovirus (HCMV) bound to platelet TLR2 results in the release of proinflammatory CD40L, interleukin- $1 \beta$, and vascular endothelial-derived growth factor (VEGF). Although HCMV does not induce platelet adhesion or aggregation, enhanced platelet-neutrophil heterotypic aggregates and neutrophil activation are observed in the presence of HCMV-treated platelets (Assinger et al., 2014). In addition, antibodies developed against influenza $\mathrm{H} 1 \mathrm{~N} 1$ virus have been shown to activate human platelets independently through both FcrRIIa signaling and thrombin generation (Boilard et al., 2014). Finally, dengue virus infection is characterized by profound hemorrhagic fever and thrombocytopenia in humans. In a rhesus macaque model infected with dengue virus, platelets were shown to be engulfed by monocytes with observed increased permeability of the endothelium (Onlamoon et al., 2010). In general, these studies provide evidence that by recognizing bacterial, drug, or viral components, platelets can mediate prothrombotic or proinflammatory pathways through varying host defense mechanisms (Fig. 2).

\section{Platelets in Cancer Metastasis}

Although not originally appreciated as being associated with platelet function, it is now well recognized that the progression of tumors in cancer patients is accompanied by increased risk of thrombotic episodes (Khorana and Fine, 2004; Khorana et al., 2008; Khorana and Connolly, 2009; Lyman and Khorana, 2009). Current evidence supports an important role for platelet regulation of tumor growth and metastasis with platelet-tumor cross-talk contributing to increased tumor metastasis, angiogenesis, growth, proliferation, and even enhanced platelet activation. Platelets are now recognized to be a major source of metastatic and proangiogenic or survival growth factors (Assoian et al., 1983), such as transforming growth factor- $\beta 1$ and VEGF.
Mechanistically, platelet-derived transforming growth factor- $\beta 1$ has been observed to act through the p-Smad signaling pathway to induce phenotypic conversion in cancer cells, such as the transition from epithelial to mesenchymal-like cells. Mice exposed to human colon carcinoma cells (HT29) cocultured or primed with human platelets exhibited a higher incidence of lung metastases compared with untreated HT29 cells. Interestingly, ASA administration to mice has been shown to prevent the increased rate of lung metastasis in vivo as well as downregulating E-cadherin and upregulating transcription factor Twist1 that is associated with metastatic cancer (Guillem-Llobat et al., 2016). In addition to the prometastatic role of platelets, platelets also promote angiogenesis, a fundamental process for tumor growth and survival, through the secretion of VEGF released from $\alpha$-granules, which acts on the VEGF receptor, VEGF-R2, on endothelial cells (Möhle et al., 1997; Italiano et al., 2008). Successful metastasis is now known to rely on cancer cell adhesion to platelets, which can be mediated by surface proteins, including P-selectin and integrin $\alpha_{\mathrm{IIb}} \beta_{3}$.

In addition to regulation of tumor function and metastasis by platelets, tumor cells can also directly trigger platelet activation, through either the induction of agonists $\left(\mathrm{TxA}_{2}\right.$ and $\left.\mathrm{ADP}\right)$ or direct physical contact with platelets (Grignani et al., 1989; Zucchella et al., 1989; Kato et al., 2005; Mitrugno et al., 2014). Podoplanin (PDPN), a transmembrane sialoglycoprotein, is highly expressed on metastatic tumor cells and can interact with C-type lectin-like receptor 2 (CLEC-2), a hemiimmunoreceptor tyrosine-based activation motif (ITAM) on the platelet surface, to induce platelet activation and in turn further promote tumor growth and metastasis. Mice administered with anti-PDPN antibody, MS-1, which prevented PDPN/CLEC-2 interaction, exhibited a significant reduction in tumor metastasis and growth (Takagi et al., 2013). In summary, the mechanistic and cellular contributions of platelets to tumor survival and metastasis suggest the validity of targeting platelets in cancer as a new avenue for therapy.

\section{Regulators of Platelet Activation and Signaling}

\section{A. G Protein-Coupled Receptors}

GPCRs are seven-transmembrane receptors with an intracellular $\mathrm{C}$ terminus and an extracellular $\mathrm{N}$ terminus (Dohlman et al., 1987; Kroeze et al., 2003; Woulfe, 2005). GPCRs signal through physical interaction with heterotrimeric $G$ proteins (Moers et al., 2003), which are located on the surface of the internal membrane (Wong et al., 1990). G proteins associated with GPCRs can be categorized into four families, $G_{s}, G_{i}, G_{q}$, and $G_{12 / 13}$, accordingly to the $\alpha$ subunit identities and functions (Wettschureck et al., 2004). G protein selectivity and resultant function in the platelet are not always obvious based on receptor activation, because many GPCRs can 
be stimulated by more than one platelet agonist and coupled to single or multiple $\mathrm{G}$ protein families (Woulfe, 2005; Li et al., 2010). A number of GPCRs are expressed on the surface of the platelet, and activation of these receptors by their respective ligands dictates the extent of activation (Fig. 3) or inhibition of platelets in the vessel.

\section{Protease-Activated Receptors 1 and 4.} Protease-activated receptors (PARs) are widely expressed on platelets and are primarily activated by the potent serine protease thrombin (Ossovskaya and Bunnett, 2004; Arachiche and Nieman, 2017). In addition to thrombin, other serine proteases, such as calpain, granzyme, and factor Xa, are able to activate PAR1 and PAR4 (Zhao et al., 2014). The PAR family of GPCRs is comprised of four members: PAR1, PAR2 (not expressed on platelets), PAR3 (not expressed on human platelets), and PAR4; and the general mechanism of PAR activation is summarized as follows: 1 ) the $\mathrm{N}$ terminus is proteolytically cleaved to expose the tethered ligand, and 2) the newly formed $\mathrm{N}$-terminal exodomain bends over and binds to extracellular loop 2 of the receptor, leading to receptor activation, $G$ protein activation, and downstream signal transduction (Seeley et al., 2003). Part of the challenge in studying platelet activation is that human platelets express both PAR1 and PAR4 on its surface, whereas most vertebrates below primate express PAR3 and PAR4 on their platelet surface (Ossovskaya and Bunnett, 2004).
Whereas PAR1 and PAR4 are activated by the same ligand and share similar binding to $\mathrm{G} \alpha_{\mathrm{q}}$ and $\mathrm{G} \alpha_{13}$, they only share $27 \%$ amino acid sequence identity, suggesting that PAR 1 in the human cannot be directly compared with PAR4 in either the human or mouse models of platelet activation and signaling (Xu et al., 1998). Compared with PAR1, PAR4 cleavage by thrombin is not as efficient if expressed by itself and needs 10 times more thrombin to be activated (Jacques and Kuliopulos, 2003; Nieman, 2008). However, the inherent coexpression of PAR1 and PAR4 on human platelets is postulated to potentially enhance the PAR4 cleavage rate by approximately 6 - to 10 -fold, suggesting that dimerization or oligomerization of the PARs on the surface of the platelet may play an important role in regulation of platelet activation (Jacques and Kuliopulos, 2003; Nieman, 2008; Arachiche et al., 2013).

PAR1 and PAR4 in human platelets signal through the $\alpha$ subunit of heterotrimeric $\mathrm{G}_{\mathrm{q}}$ and $\mathrm{G}_{13}$ proteins $\left(\mathrm{G} \alpha_{\mathrm{q}}\right.$ and $\mathrm{G} \alpha_{13}$ ); however, the coupling of PARs to $\mathrm{G} \alpha_{\mathrm{i}}$ in platelets has not been confirmed to date (Holinstat et al., 2006, 2009; Kim et al., 2006; McCoy et al., 2012; Arachiche and Nieman, 2017). G $\alpha_{\mathrm{q}}$ transmits its signal primarily through the activation of phospholipase $\mathrm{C}$ (PLC) $\beta$, which subsequently induces second messenger signaling through formation of $\mathrm{IP}_{3}$ and DAG (Hung et al., 1992; Offermanns et al., 1997; Holinstat et al., 2009; Stalker et al., 2012; Edelstein et al., 2014). $\mathrm{IP}_{3}$ stimulates the intracellular calcium mobilization, and

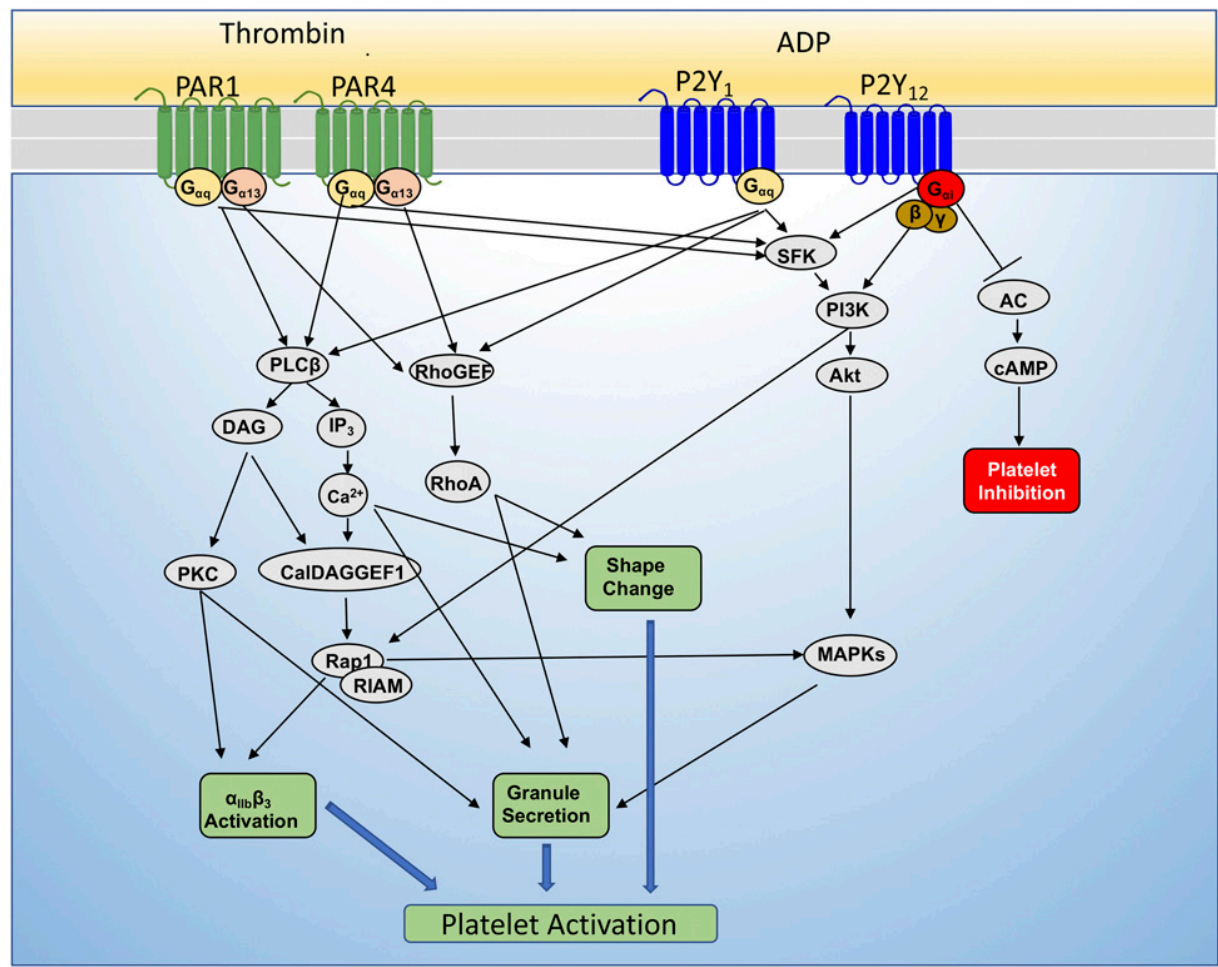

Fig. 3. GPCR signaling in platelet function. Platelets express thrombin (PAR1/PAR4) and purinergic ( $\mathrm{P} 2 \mathrm{Y}_{1}$ and $\mathrm{P} 2 \mathrm{Y}_{12}$ ) receptors. Each receptor is coupled to either $\mathrm{G}_{\mathrm{i}}, \mathrm{G}_{\mathrm{q}}$, or $\mathrm{G}_{13}$, which is involved in platelet activation (granule release, integrin activation). 
DAG activates protein kinase C, respectively (Hung et al., 1992; Offermanns et al., 1997). As a result, a downstream integrin activation pathway is generated, including a $\mathrm{Ca}^{2+}$-dependent guanine nucleotide exchange factor for Rap1, an adaptor Rap1-GTPinteracting adaptor molecule, and the proteins kindlin and talin that directly bind to the cytosolic domain of the integrin $\alpha_{\mathrm{IIb}} \beta_{3}$ (Shattil et al., 2010). In addition to activation of $\alpha_{\mathrm{IIb}} \beta_{3}$, a number of other platelet responses are regulated by the $\mathrm{G} \alpha_{\mathrm{q}}$-mediated pathway, including granule secretion and platelet aggregation (Ossovskaya and Bunnett, 2004; Arachiche and Nieman, 2017). The signal transduced through $\mathrm{G} \alpha_{13}$ activates the Rho guanine nucleotide exchange factor p111RhoGEF, resulting in the activation of RhoA, and its effectors, including Rho-activated kinase and LIMkinase, to stimulate platelet shape change (Moers et al., 2003; Huang et al., 2007). Although shape change is thought to be predominantly regulated by $\mathrm{G} \alpha_{13}$, activation of $\mathrm{G} \alpha_{\mathrm{q}}$ has also been shown to be involved in platelet shape change downstream of myosin light chain kinase in a $\mathrm{Ca}^{2+}$-dependent manner (Offermanns, 2001).

Whereas PAR1 and PAR4 share some overlapping signaling events, each receptor appears to signal platelet activity through a unique set of pathways with differing kinetics. The intracellular $\mathrm{Ca}^{2+}$ signaling duration differs dramatically between PAR1 and PAR4 (Covic et al., 2000). Compared with PAR1, PAR4 has sustained $\mathrm{Ca}^{2+}$ signaling, which is beneficial for stable clot formation and fibrinogen fully spreading (Mazharian et al., 2007). Membrane lipid signaling identified on platelets is regulated via PAR1 and PAR4 differently. Membrane-bound neutral sphingomyelinase, which regulates platelets by inducing the mitogen activated protein kinase pathway, is increasingly associated with PAR4, but not PAR1, in human platelets when responding to thrombin (Chen et al., 2013). Compared with PAR1, stimulation of PAR4 induces significantly higher $\mathrm{TxA}_{2}$ formation, which is a metabolite of lipid membrane AA and activates platelets via $\mathrm{TP} \alpha$ (Holinstat et al., 2011). Integrin $\alpha_{\mathrm{IIb}} \beta_{3}$ is activated by PAR1, instead of PAR4, through phosphoinositide 3-kinase (PI3K) to induce platelet aggregation (Holinstat et al., 2007; Voss et al., 2007). All of the above leads to the rejection of the original hypothesis that PAR4 is just a redundant receptor for PAR1, reinforcing the concept that pharmacological perturbation of each receptor is warranted to develop therapeutic target (to be discussed in section Platelet Pharmacological Targets and Interventions of this review).

2. Purinergic Receptors $P 2 Y_{1}$ and $P 2 Y_{12}$. The purinergic receptors can be classified as either adenosine receptors (P1) or nucleotide receptors (P2). Ligand-gated ion channels (P2X) and GPCRs (P2Y) are the two major members of the P2 family (Murugappa and Kunapuli, 2006). Human platelets express the two P2Y receptor subtypes, $\mathrm{P}_{2} \mathrm{Y}_{1}$ and $\mathrm{P}_{2} \mathrm{Y}_{12}$, that are activated by
$\mathrm{ADP}$ (Fig. 3) and are prime targets for antiplatelet therapy (Murugappa and Kunapuli, 2006; Yeung and Holinstat, 2012). Optimal platelet activation by ADP requires both receptors, by which each receptor subtype contributes uniquely through its associated $\mathrm{G}$ proteins. P2Y $Y_{1}$ is a GPCR coupled to $\mathrm{G} \alpha_{\mathrm{q}}$ that mediates activation of $\mathrm{PLC} \beta$ and subsequent production of $\mathrm{IP}_{3}$ and DAG, causing $\mathrm{Ca}^{2+}$ release and protein kinase $\mathrm{C}$ activation (Ayyanathan et al., 1996; Murugappa and Kunapuli, 2006). Interestingly, shape change is also observed in P2Y $Y_{1}$ activation, suggesting $\mathrm{G} \alpha$ is also involved in shape change as observed in $\mathrm{G} \alpha_{13}$. This is most likely due to calcium or calmodulin, or Rac-dependent contractile signaling in the $\mathrm{G} \alpha_{\mathrm{q}}$ pathway (Offermanns et al., 1997; Soulet et al., 2005).

In contrast to the wide tissue distribution of $\mathrm{P}_{2} \mathrm{Y}_{1}$, being expressed in platelets, central nervous system, and peripheral tissues, $\mathrm{P}_{2} \mathrm{Y}_{12}$ is only found in platelets and brain, which has made it an appealing antithrombotic drug target (Murugappa and Kunapuli, 2006). $\mathrm{P} 2 \mathrm{Y}_{12}$ is coupled to both $\mathrm{G} \alpha_{\mathrm{q}}$ and $\mathrm{G} \alpha_{\mathrm{i}}$, which results in not only PLC $\beta$ activation, but also inhibition of adenylyl cyclase (Hollopeter et al., 2001; Kauskot and Hoylaerts, 2012). The activation of $\mathrm{P}_{2} \mathrm{Y}_{12}$ has been demonstrated to induce $\mathrm{G} \beta \gamma$ activation that mediates dense granule secretion through the PI3K/Akt pathway (Kauffenstein et al., 2001; Murugappa and Kunapuli, 2006). Although many GPCR targets exist on the surface of the platelet, at least four Food and Drug Administration (FDA)approved drugs have been developed to target $\mathrm{P}_{2} \mathrm{Y}_{12}$, as a standard-of-care treatment of a number of thrombotic conditions, used either as monotherapy or polytherapy in conjunction with ASA (referred to as dual antiplatelet therapy).

3. Prostaglandin Receptors $T P \alpha, I P, E P$, and $D P$. Prostaglandins (PGs) are lipid-derived autacoids formed by a 20-carbon unsaturated fatty acid, AA, sequential metabolism catalyzed by COX, and prostaglandin synthase enzymes (Hata and Breyer, 2004). TxA $2, \mathrm{PGD}_{2}, \mathrm{PGE}_{2}$, and prostacyclin $\left(\mathrm{PGI}_{2}\right)$ are four predominant bioactive prostaglandins formed in vivo that are known to regulate platelet function through their respective receptors, $\mathrm{TP} \alpha$, prostaglandin $\mathrm{D}_{2}$ receptor $1\left(\mathrm{DP}_{1}\right)$, prostaglandin $\mathrm{E}_{2}$ receptors $\left(\mathrm{EP}_{1-4}\right)$, and prostacyclin receptor (IP) (Fig. 4). $\mathrm{TxA}_{2}$, derived from COX-1 oxidation of AA following phospholipase $\mathrm{A}_{2}$ activation, is a potent agonist for platelet shape change and aggregation (Woulfe, 2005). Although there are two variants of the TPs, TP $\alpha$ and TP $\beta$ (Habib et al., 1999), $\mathrm{TxA}_{2}$ interacts with the $\mathrm{TP} \alpha$ receptor coupled to $\mathrm{G} \alpha_{\mathrm{q}}$ and $\mathrm{G} \alpha_{13}$ on platelets (Raychowdhury et al., 1994) to mediate the PLC $\beta$ and RhoA pathways (Woulfe, 2005; Gong et al., 2010). In contrast, $\mathrm{PGD}_{2}$ activates $\mathrm{DP}_{1}$ coupled to $\mathrm{G} \alpha_{\mathrm{s}}$ that stimulates adenylyl cyclase to enhance cAMP production to inhibit platelet activation.

Interestingly, $\mathrm{PGE}_{2}$ exhibits a biphasic, dose-dependent effect on platelet function through its receptors, $\mathrm{EP}_{1}, \mathrm{EP}_{2}$, $\mathrm{EP}_{3}$, and $\mathrm{EP}_{4}$. Each of the $\mathrm{EP}$ receptors is unique such that 


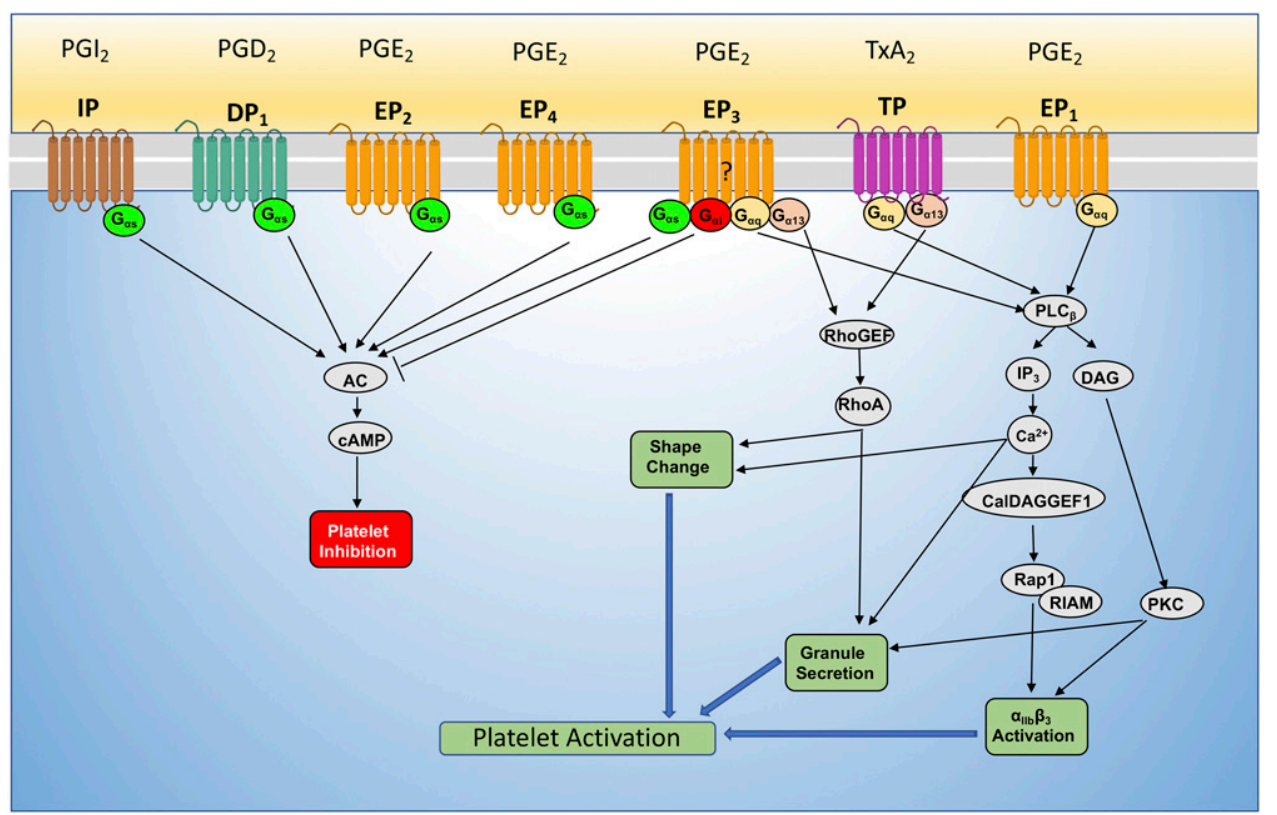

Fig. 4. Prostanoid receptors on human platelets. Each prostanoid receptor, IP, DP, $\mathrm{EP}_{1-4}$, and $\mathrm{TP} \alpha$, is uniquely defined by its lipid ligands as well as its associated G proteins. Depending on the type of oxylipins or doses, platelet function can either be inhibited or activated. This is dictated by their cognate receptor activation, which is coupled to either inhibitory $\mathrm{G} \alpha_{\mathrm{s}}$ or activating $\mathrm{G} \alpha_{13}, \mathrm{G} \alpha_{\mathrm{q}}$, and $\mathrm{G} \alpha_{\mathrm{i}}$.

it has different binding affinity for $\mathrm{PGE}_{2}$ as well as coupled to different $\mathrm{G}$ proteins, allowing $\mathrm{PGE}_{2}$ to either activate or inhibit platelet function at low or high concentrations, respectively (Kauskot and Hoylaerts, 2012). Whereas $\mathrm{EP}_{1}$ and $\mathrm{EP}_{2}$ are low-affinity receptors $\left(K_{\mathrm{d}}>10 \mathrm{nM}\right), \mathrm{EP}_{3}$ and $\mathrm{EP}_{4}$ bind to $\mathrm{PGE}_{2}$ with higher affinity $\left(K_{\mathrm{d}}<10 \mathrm{nM}\right)$ (Abramovitz et al., 2000). Furthermore, $\mathrm{EP}_{2}$ and $\mathrm{EP}_{4}$ are coupled to $\mathrm{G} \alpha_{\mathrm{s}}$, which activates adenylyl cyclase to evoke cAMP generation, resulting in inhibition of platelet function. $\mathrm{EP}_{1}$ is reported to couple to $\mathrm{G} \alpha_{\mathrm{q}}$ based on the observation of increased calcium mobilization (Sugimoto and Narumiya, 2007). Although $\mathrm{EP}_{3}$ has been predominantly demonstrated to associate with either $\mathrm{G} \alpha_{\mathrm{i}}$ or $\mathrm{G} \alpha_{\mathrm{q}}$, there are reports of $\mathrm{G} \alpha_{\mathrm{s}}$ or $\mathrm{G} \alpha_{13}$ coupling. Thus, the exact $\mathrm{G}$ proteins involved in $\mathrm{EP}_{3}$ signaling are still unclear. Overall, the dual effect regulated by at least four GPCRs gives the platelet a significant level of control over the overall $\mathrm{PGE}_{2}$ effect on platelet function and activation.

$\mathrm{PGI}_{2}$ or prostacyclin is a known inhibitor of platelet activation derived from AA (Kauskot and Hoylaerts, 2012). $\mathrm{PGI}_{2}$ maintains platelets in a quiescent state in the absence of vascular injury or agonist activation (Cheng et al., 2002; Woulfe, 2005; Tourdot et al., 2017) by activating its receptor, IP, coupled to $\mathrm{G} \alpha_{\mathrm{s}}$ to stimulate adenylyl cyclase and subsequent cAMP formation and protein kinase A activation (Kauskot and Hoylaerts, 2012).

\section{B. Integrin Receptors $\alpha_{I I b} \beta_{3}, \alpha_{2} \beta_{1}$}

In addition to GPCRs, platelets express multiple nonGPCRs, including several integrin receptors, such as fibrinogen receptor, $\alpha_{\mathrm{IIb}} \beta_{3}$; collagen receptor, $\alpha_{2} \beta_{1}$; and laminin receptor, $\alpha_{6} \beta_{1}$, which share similar signaling mechanisms (Li et al., 2010). The fibrinogen receptor
$\alpha_{\mathrm{IIb}} \beta_{3}$ is the most abundant surface integrin $(40,000$ 80,000 copies per cell) with a $148-\mathrm{kDa} \alpha_{\mathrm{IIb}}$ and a $95-\mathrm{kDa}$ $\beta_{3}$ subunit (Kauskot and Hoylaerts, 2012). Normally, $\alpha_{\mathrm{IIb}} \beta_{3}$ is at low affinity or resting state; however, upon platelet response to activating agonists, $\alpha_{\mathrm{IIb}} \beta_{3}$ undergoes an inside-out process by which it switches to an activated state with high affinity ( $\mathrm{Li}$ et al., 2010) for fibrinogen. The shift in integrin affinity or conformational change is facilitated by the binding of talin and kindlin, to the intracellular $\beta_{3}$ domain (Shattil et al., 2010). The underlying mechanism accommodating the talin and kindlin binding is attributed to Rap1 activation and Rap1-GTP-interacting adaptor molecule mediated by $\mathrm{Ca}^{2+}$-dependent guanine nucleotide exchange factor for Rap1 (Lafuente et al., 2004). In addition, the platelet can be secondarily activated by direct $\alpha_{\mathrm{IIb}} \beta_{3}$ interaction with fibrinogen, $\mathrm{vWF}$, and other matrix proteins, to transmit signals to the cytoplasmic and cytoskeletal domains. This process is termed outside-in signaling, by which matrix proteins directly activate $\alpha_{\mathrm{IIb}} \beta_{3}$.

Furthermore, integrin $\alpha_{2} \beta_{1}$ is one of two receptors expressed on the platelet that binds with high affinity to collagen (Cosemans et al., 2008). $\alpha_{2} \beta_{1}$ has primarily been recognized in providing platelets firm adhesion to the subendothelial wall following platelet translocation along the vessel wall (see section General Function of Platelets). The role played by $\alpha_{2} \beta_{1}$ in the collageninduced platelet activation still remains unclear. Many of the contradicting results on whether collagen binding to $\alpha_{2} \beta_{1}$ is critical for platelet activation were due to differing experimental conditions. In contrast, one general consensus was that genetic ablation or pharmacological inhibition of $\alpha_{2} \beta_{1}$ integrin in platelets 
delayed platelet response to collagen without affecting the final extent of activation compared with controls. It has been demonstrated that, analogous to $\alpha_{\mathrm{IIb}} \beta_{3}$ binding to fibrinogen, $\alpha_{2} \beta_{1}$ integrin undergoes a shift from low- to high-affinity state for collagen following stimulation (Jung and Moroi, 1998), supporting an inside-out signaling mechanism. In contrast, an outside-in model has also been demonstrated by which platelets spread on GFOGER motifs. Platelet spreading on $\alpha_{2} \beta_{1}$ recognition motif, GFOGER, induced activation of the Src kinases and subsequent Syk recruitment and PLC $\gamma 2$ activation (Inoue et al., 2003). This observation was also supported by PLC $\gamma 2$-deficient mouse platelets, which exhibited limited spreading on GFOGER-coated surface. Interestingly, this study also provided insights to the underlying intracellular signaling events involved in $\alpha_{2} \beta_{1}$-mediated platelet adhesion and spreading. $\alpha_{2} \beta_{1}$-mediated spreading was demonstrated to share similar signaling pathways as the outside-in models of $\alpha_{\mathrm{IIb}} \beta_{3}$ and Fc $\gamma$ RIIa.

\section{Immunoreceptor Tyrosine-Based Activation Motif Receptors}

Platelets express three (hemi)ITAM receptors, GPVI, Fc $\gamma$ RIIa, and CLEC-2 (Fig. 5). Although both GPVI and Fc $\gamma$ RIIa belong to the Ig family of receptors and signal through the dual ITAM consensus sequence (L/I/V/S)-XY-X-X-(L/V) (Kauskot and Hoylaerts, 2012) in platelets, they are structurally distinct in their relation to ITAM localization and activation. GPVI noncovalently associates with the $\mathrm{Fc}$ receptor $\gamma$-chain $(\mathrm{Fc} \gamma \mathrm{R})$ containing the ITAM, whereas Fc $\gamma$ RIIa possesses the ITAM consensus sequence in its cytoplasmic tail (Clemetson and Clemetson, 2001; Bergmeier and Stefanini, 2013). Upon GPVI and Fc $\gamma$ RIIa cross-linking or clustering, the ITAM is phosphorylated by Src family kinases, Lyn and Fyn, followed by recruitment and activation of proximal effector tyrosine kinase Syk. Syk initiates a downstream signaling cascade that includes the phosphorylation of transmembrane adapter linker for activated T cells (LAT) and assembly of a signalosome. The core of the signalosome consists of phosphorylated transmembrane adaptor LAT (Pasquet et al., 1999) and cytosolic adaptors, Src homology 2 domaincontaining leukocyte phosphoprotein of $76 \mathrm{kDa}$ bound to Gads or Grb2 (Judd et al., 2002; Hughes et al., 2008). These three proteins associate with a number of signaling molecules, including Bruton tyrosine kinase (Quek et al., 1998), GTP exchange factors (Vav1 and Vav3) (Pearce et al., 2002, 2004), small GTPase Rac, and the $\alpha$ and $\beta$ isoforms of PI3K, which are critical for the recruitment and activation of PLC $\gamma 2$. For instance, the pleckstrin homology domain of PLC $\gamma 2$ facilitates its recruitment to the plasma membrane through its binding of the PI3K product, phosphatidylinositol $(3,4,5)$ triphosphate. This binding plays an important role in the maximal activation of PLC $\gamma 2$, which liberates second messengers DAG and $\mathrm{IP}_{3}$ from phosphatidylinositol-4,5bisphosphate.

CLEC-2 is a novel member of the ITAM platelet receptor family that has a carbohydrate-like extracellular domain. Currently, CLEC-2 is found to be important in lymphatic development and thrombosis. Mice lacking CLEC-2 in platelets exhibit impaired platelet aggregate formation and lower susceptibility to arterial thrombosis (May et al., 2009; Suzuki-Inoue et al., 2010; Herzog et al., 2013). Unlike the ITAM receptors, CLEC-2 has a single YxxL motif in its cytoplasmic tail that also employs the same signaling effectors as the ITAMs; however, differences of ITAM and hemi(ITAM) signaling have been reported. Syk has been shown to phosphorylate the hemi(ITAM), followed by Src family kinase recruitment and activation of LAT (Stegner et al., 2014). TxA has been shown to play an important role in CLEC-2induced Syk and PLC $\gamma 2$ phosphorylation. In addition, activation of $\mathrm{ADP}$ and PAR receptors potentiate CLEC-2 signaling (Badolia et al., 2017).

\section{Enzymes Targeted for Regulation of Platelet Function}

Polyunsaturated fatty acids (PUFAs), including AA, docosahexaenoic acid, docosapentaenoic acid, dihomo$\gamma$-linolenic acid (DGLA), eicospentaenoic acid (EPA), and linoleic acid, are hydrolyzed by cytocolic phosholipase $\mathrm{A}_{2}$ $\left(\mathrm{cPLA}_{2}\right)$ in platelets, and the subsequent free fatty acids are metabolized by COXs, LOXs, and cytochrome P450 (CYP450) to generate structurally distinct oxylipins that exhibit either pro- or antiplatelet functions (Yeung et al., 2017).

1. Cyclooxygenase-1. COX-1 is highly expressed in platelets and generates a number of $\mathrm{PGs}$, including $\mathrm{TxA}_{2}$, through PUFA metabolism (Rouzer and Marnett, 2009). Through COX-1, AA is transformed to series 2 PGs (including $\mathrm{TxA}_{2}, \mathrm{PGD}_{2}, \mathrm{PGE}_{2}$, and $\mathrm{PGI}_{2}$ ), which are either prothrombotic or antithrombotic (Ricciotti and FitzGerald, 2011; Chandrasekharan et al., 2016; Yeung et al., 2017). In addition, COX-1 converts the $\omega-6$ PUFA, DGLA, to series 1 PGs (including TxA $1, \mathrm{PGD}_{1}$, and $\mathrm{PGE}_{1}$ ) that are known to inhibit platelet activity both in vivo and in vitro (Lagarde et al., 2013; Sergeant et al., 2016). Similarly, the $\omega$-3 PUFA, EPA, reacts with COX-1 to form series $3 \mathrm{PGs}$ (including $\mathrm{TxA}_{3}, \mathrm{PGD}_{3}$, $\mathrm{PGE}_{3}$, and $\mathrm{PGI}_{3}$ ) to inhibit platelet functions (Fischer and Weber, 1985; Krämer et al., 1996).

2. 12-Lipoxygenases. 12-LOX can be categorized into one of three forms (platelet, leukocyte, and epithelial) based on its cellular expression, and, among which, the platelet-type 12-LOX is found in all mammalian species (Funk et al., 1990). 12(S)-LOX, rather than 12(R)-LOX, is the predominant 12-LOX protein reported to regulate platelet function (Yeung et al., 2017). 12-LOX converts AA to 12(S)-hydroperoxyeicosatetraenoicacid, which is then quickly reduced to 12(S)-HETE (Yeung et al., 2017). 12(S)HETE has been shown to have contradicting roles in 


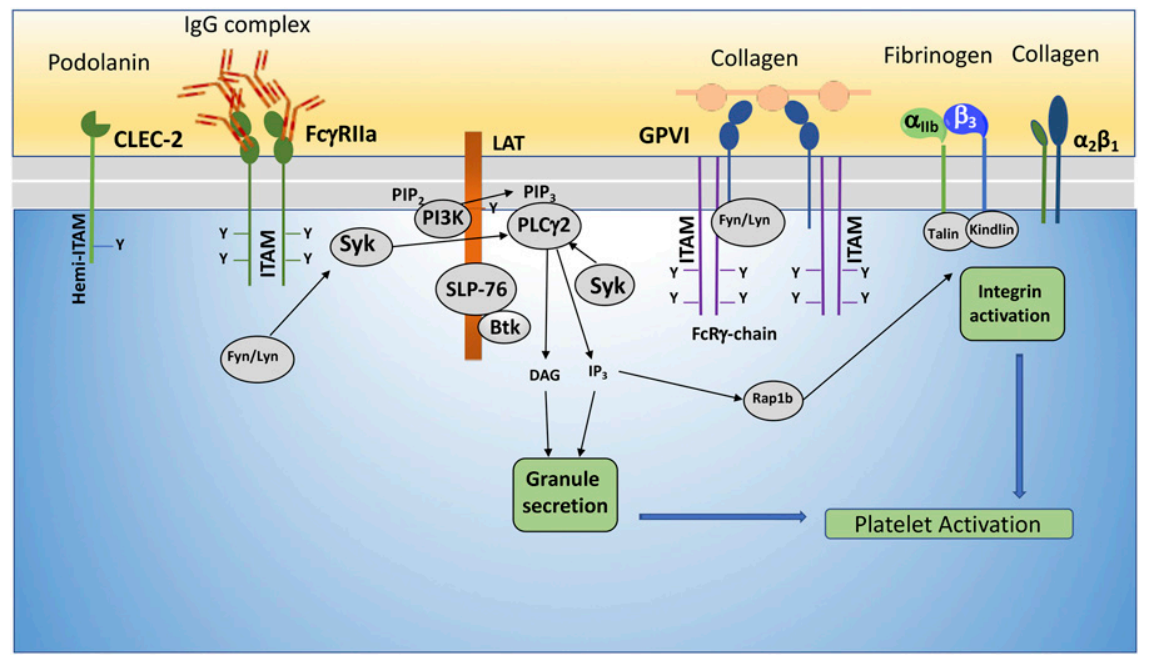

Fig. 5. ITAM and integrin receptors on platelets. GPVI, Fc $\gamma \mathrm{II}$, and CLEC-2 belong to a class of hemi(ITAM) receptors that are involved in platelet activation. Whereas GPVI and $\alpha_{2} \beta_{1}$ are activated by collagen, Fc $\gamma$ III recognizes IgG immune complexes to induce integrin $\alpha_{\text {IIb }} \beta_{3}$ activation. CLEC-2 contains a single YxxL motif that is activated by podoplanin. Ligand binding to GPVI or Fc $\gamma$ IIIa results in Syk and subsequent PLC $\gamma 2$ activation, leading to platelet aggregation, mediated by the active conformation of integrin $\alpha_{\mathrm{IIb}} \beta_{3}$.

platelet function. 12(S)-HETE has been reported to exert antiplatelet effects by inhibiting $\mathrm{cPLA}_{2}$ (Chang et al., 1985; Yamamoto, 1992) and preventing $\mathrm{TxA}_{2}$ binding to its TP $\alpha$ receptor (Fonlupt et al., 1991). Conversely, 12(S)HETE has been reported to be proaggregatory or prothrombotic by inducing $\mathrm{TxA}_{2}$ and dense granule secretion, as well as inhibiting $\mathrm{PGE}_{1}$-induced cAMP formation (Calzada et al., 1997; Yeung et al., 2012, 2016; Adili et al., 2017). Moreover, other 12-LOX-derived metabolites, including 12(S)-hydroxyeicosapentanoic acid from EPA, 11/14-hydroxydocosahexaenoic acid from docosahexaenoic acid, 11/14-hydroxydocosapentaenoic acid from docosapentaenoic acid, and 12-hydroxyeicosatrienoic acid from DGLA, are shown to have antithrombotic effect in vivo and in vitro (Takenaga et al., 1986; Sun et al., 2015; Yeung et al., 2016).

3. Cyclic Nucleotide Phosphodiesterases. There are at least seven isoenzymes of phosphodiesterases (PDEs) distinguished by their structural and enzymatic properties; however, platelets express PDE2, PDE3, and PDE5. PDEs regulate intracellular levels of cyclic nucleotides, such as cGMP and cAMP, in the platelets through hydrolysis (Cheung et al., 1996; Degerman et al., 1997). As a result of decreased cGMP or cAMP, platelets are prevented from being inhibited. Thus, PDEs are major targets of antiplatelet therapy to regulate platelet function through modulation of endogenous cAMP or cGMP (Conti et al., 1995; Manganiello et al., 1995).

\section{Platelet Pharmacological Targets and Interventions}

Antiplatelet agents, whether administered as a mono- or polytherapy, are the cornerstone of clinical treatment of arterial thrombotic events and ischemic stroke. Although antiplatelet targets have been limited to primarily COX-1, $\mathrm{P} 2 \mathrm{Y}_{12}$ receptor, and integrin $\alpha_{\mathrm{IIb}} \beta_{3}$, recent advances have revealed a number of newer targets that have led to novel antiplatelet drugs, either currently in use or in preclinical or early clinical stages of development. These agents target surface receptors (glycoproteins and GPCRs), oxygenases, and PDEs (Fig. 6 ; Table 1). With the availability of several antiplatelet agents with different safety and efficacy profiles, finding the best antithrombotic drug to rapidly and potently curtail thrombotic-associated events without increasing serious bleeding is becoming an attainable goal.

\section{A. Oxygenase Inhibitors}

Platelets express two classes of oxygenases, COX-1 and 12-LOX, which generate an assortment of unique lipid mediators (oxylipins) from PUFAs that exhibit pro- or antithrombotic activity. The most abundant PUFA in the lipid bilayer is AA, which is acted upon by both oxygenases to form the prothrombotic oxylipins, $\mathrm{TxA}_{2}$ and 12(S)-HETE. Significant efforts have resulted in a number of therapeutic drugs being developed to target the formation of these prothrombotic oxylipins to prevent their potentiation of platelet activation.

Aspirin or ASA, one of the first drugs developed for prevention of thrombosis, irreversibly targets COX-1 in the platelets to block the prostanoid production from AA (Capone et al., 2010). ASA is rapidly absorbed in the upper gastrointestinal tract following oral administration, leading to measurable platelet inhibition within 60 minutes. The plasma half-life of ASA is approximately 15 minutes, and peak plasma levels are achieved 30-40 minutes after ingestion (Patrono et al., 2005; Capodanno and Angiolillo, 2016). The ISIS-2 clinical trial showed ASA therapy was associated with a significant reduction in vascular mortality in patients 


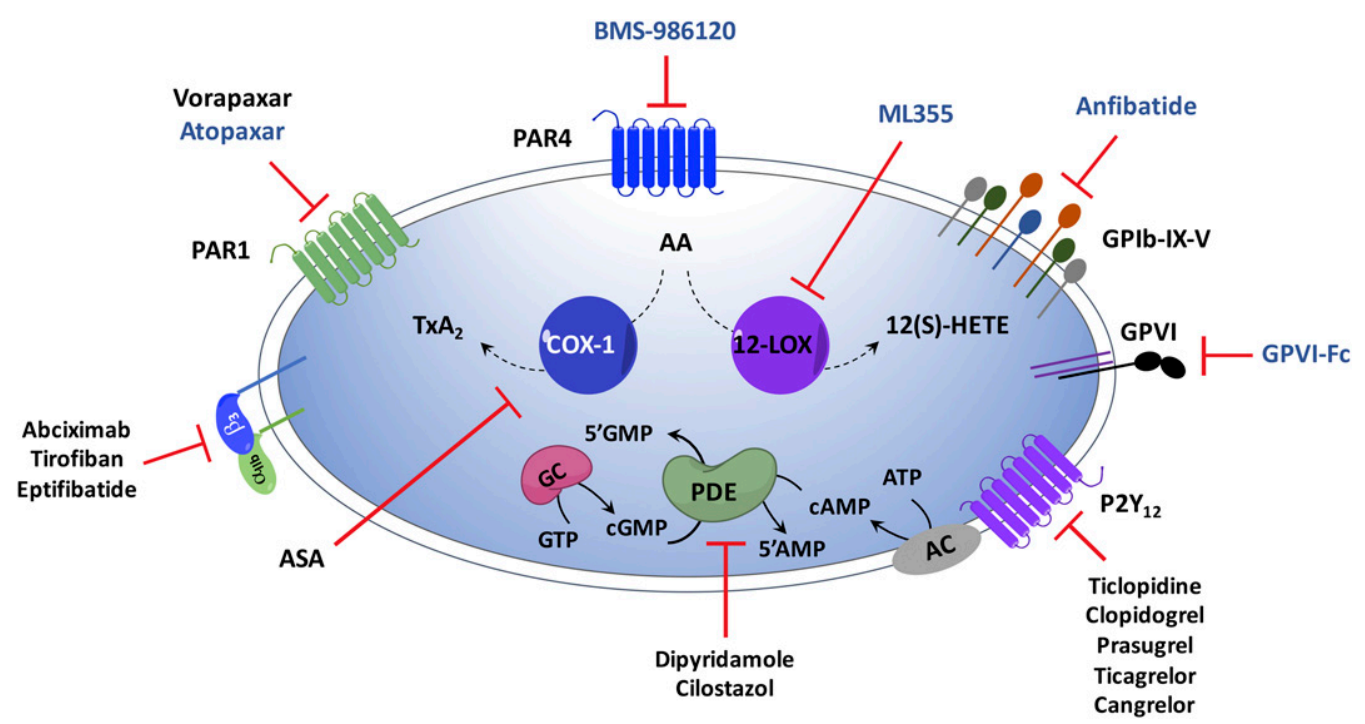

Fig. 6. The major antiplatelet targets. Drugs inhibit surface receptors, GPCRs (PAR1/4, P2Y12) and glycoproteins (integrin $\alpha_{\mathrm{IIb}} \beta_{3}$, GPVI, and GIb-IXV), oxygenases (COX-1, 12-LOX), and phosphodiesterases to regulate platelet function. Agents coded in black are currently FDA approved, whereas drugs labeled as blue are under investigation in preclinical or clinical phases.

with suspected acute MI, either as a stand-alone therapy or in a combination with streptokinase. This established ASA as the first-line therapy in patients with ST-elevation myocardial infarction, and recommended to be taken when presented with symptoms and indefinitely irrespective of treatment strategy (Levine et al., 2011; O'Gara et al., 2013). More recently, ASA has been used as a dual antiplatelet therapy with $\mathrm{P}_{2} \mathrm{Y}_{12}$ receptor inhibitors (clopidogrel, prasugrel, or ticagrelor) to prevent blood clots after percutaneous coronary interventions (PCIs). Although ASA has effectively reduced morbidity and mortality, an increase in bleeding has also been associated with its use, especially gastrointestinal hemorrhage (Huang et al., 2011).

Another approach to antiplatelet therapy is targeting 12-LOX from forming 12(S)-HETE. Initial 12-LOX inhibitors (baicaelin, nordihydroguaiaretic acid, 5,8,11,14eicosatetraynoic acid, OPC-29030, L-655,238, and BW755C) were found to be nonselective, as they were found to target $\mathrm{cPLA}_{2}, \mathrm{COX}-1, \mathrm{COX}-2$, and other LOXs (15-LOX-1, 15-LOX-2, 5-LOX) in addition to 12-LOX. Recently, a more selective 12-LOX inhibitor, ML355, has been developed with no inhibitory activity identified for 15-LOX, 5-LOX, or COX, which exhibits potent inhibition of platelet activation in vivo (Luci et al., 2010; Adili et al., 2017). Moreover, ML355, which was given orally twice per day for 2 days to wild-type mice dose dependently (1.88, $3.75,7.5,15$, and $30 \mathrm{mg} / \mathrm{kg}$ ), inhibited thrombus growth and vessel growth following FeCl3-induced mesenteric and laser-induced cremaster arteriole injury. ML355 has a favorable pharmacokinetic profile in which the maximal concentration of ML355 in plasma was approximately $57 \mu \mathrm{mol} / /$ within 30 minutes, and approximately $5 \mu \mathrm{mol} / \mathrm{l}$ was detected in plasma at 12 hours following oral administration of $30 \mathrm{mg} / \mathrm{kg}$ for 2 days. ML355 was also able to inhibit human platelet adhesion and thrombus growth over collagen-coated ex vivo flow chambers, confirming the in vivo observations (Adili et al., 2017). Importantly, bleeding diathesis based on in vivo hemostatic plug formation and tail bleeding in mice orally gavaged with $30 \mathrm{mg} / \mathrm{kg}$ ML355 was not altered. Additionally, the utility of ML355 for inhibition of a variety of thrombotic diseases was established through inhibition of immune-mediated platelet activation and prevention of HIT in an ex vivo mouse model (Yeung et al., 2014). Taken together, these preclinical studies demonstrated the potential therapeutic benefits of targeting 12-LOX with ML355 for effectively preventing thrombotic events with minimal impact on bleeding.

\section{B. ADP Receptor Inhibitors}

$\mathrm{P}_{12} \mathrm{Y}_{12}$ receptor inhibitors are divided into prodrug and active antagonists. The thienopyridines (ticlopidine, clopidogrel, and prasugrel) are FDA-approved prodrugs, whereby the active metabolites of the thienopyridine prodrugs covalently and irreversibly bind to the receptor during the entire life span of the platelets (7-10 days). Although the thienopyridines require CYP450 isoenzyme metabolism for the generation of active metabolites, the pathways leading to their active metabolites differ between the prodrugs. In contrast, the nucleoside analogs (ticagrelor and cangrelor) are active $\mathrm{P}_{2} \mathrm{Y}_{12}$ receptor antagonists that do not necessarily require metabolic conversion. The nucleoside analogs are reversible inhibitors due to their distinct binding site from ADP binding domain.

One of the first thienopyridines, ticlopidine (trade name Ticlid), which has an onset of action of 1-2 hours after a single oral dose $(250 \mathrm{mg})$, was initially shown to be useful for preventing coronary stent occlusions and strokes. Due to the serious side effects [bone marrow suppression, thrombotic thrombocytopenia purpura 


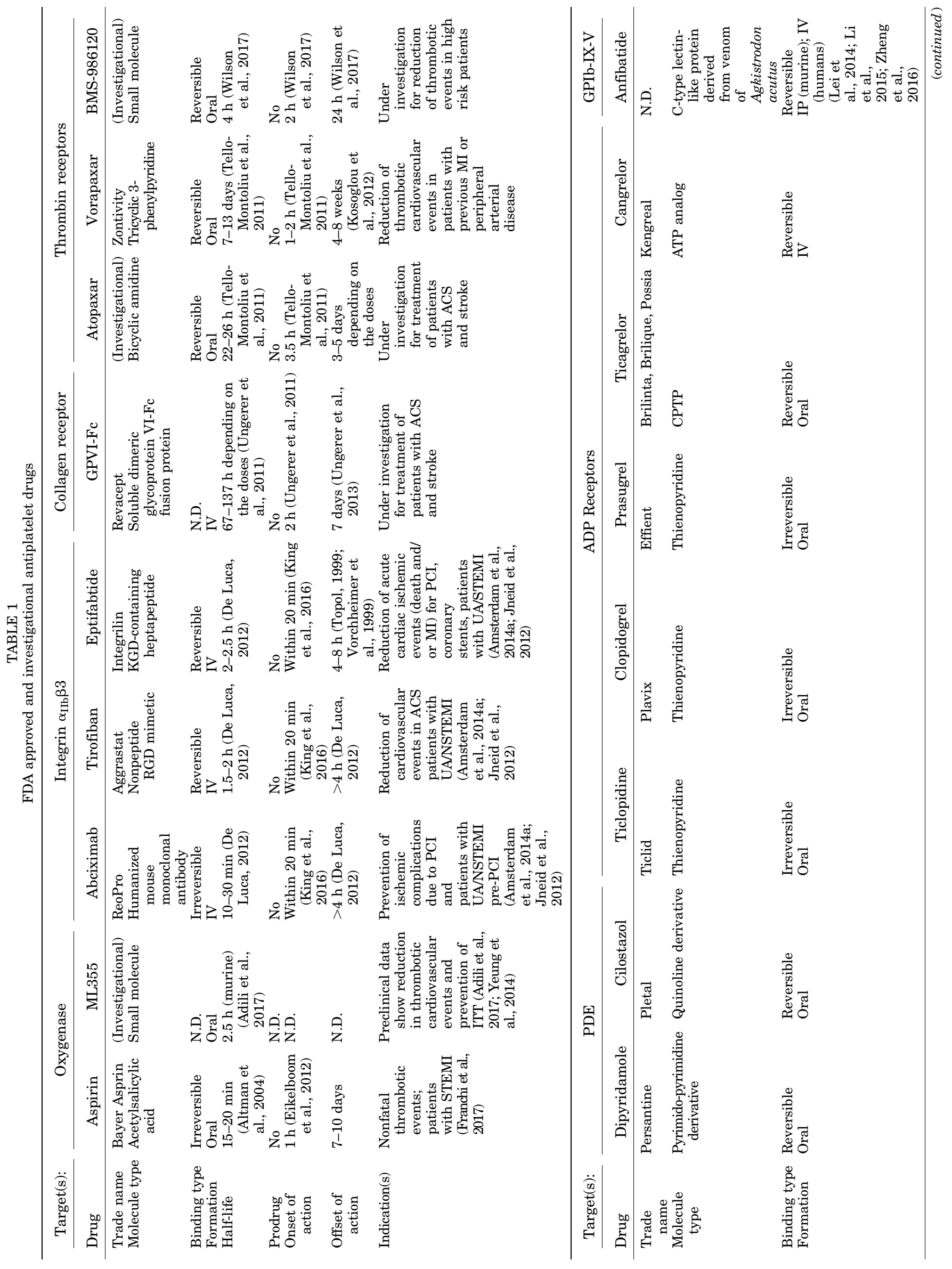




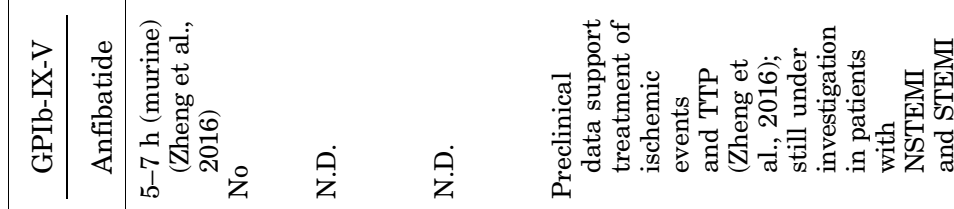

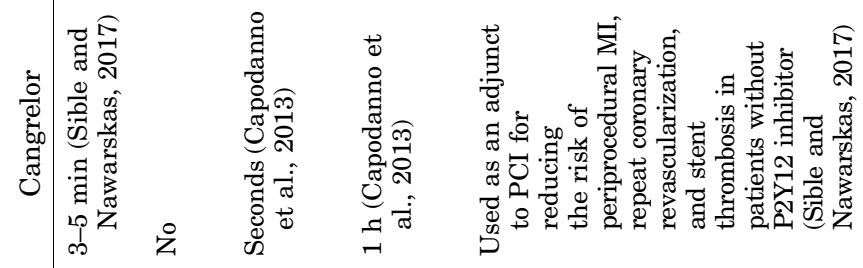

营

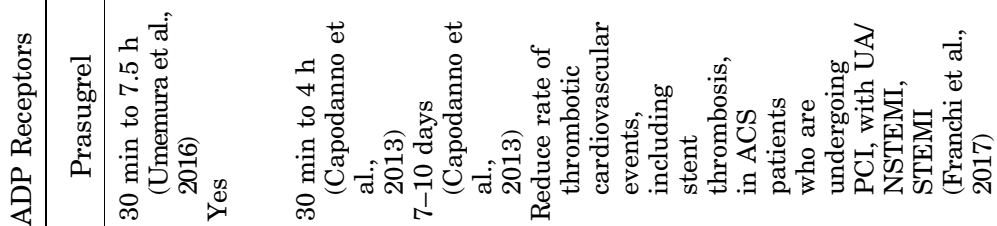

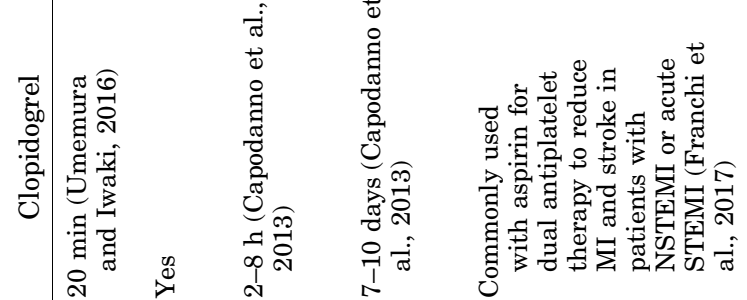

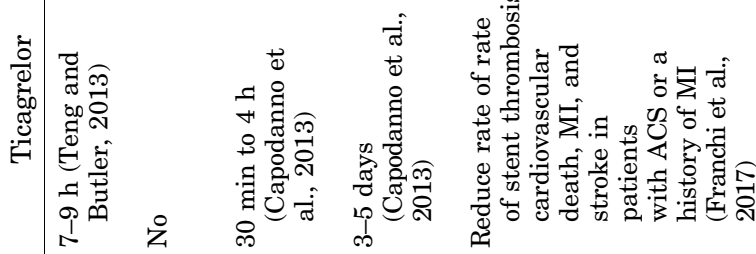

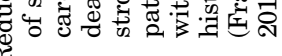

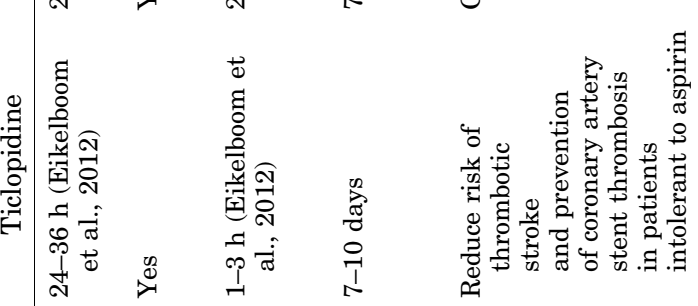

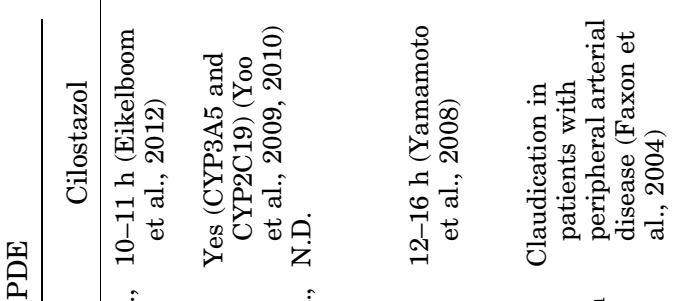

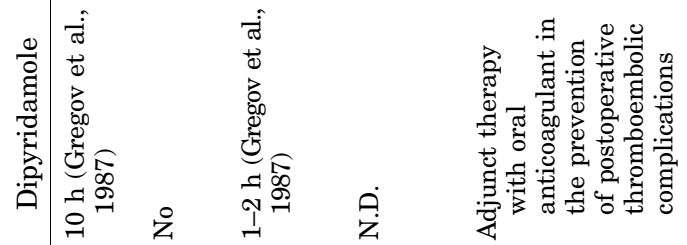

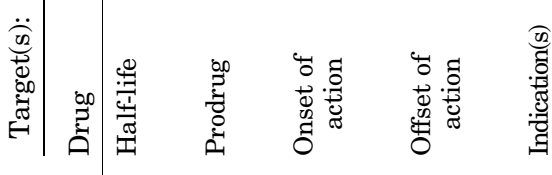


(TTP), neutropenia], use of ticlopidine was limited to patients for whom ASA was not tolerated. Because of ticlopidine's limited tolerability and significant side effects, an alternative thienopyridine analog was developed [clopidogrel (Plavix)]. Clopidogrel is currently the most widely used oral antithrombotic agent. Its irreversible effect on the $\mathrm{P}_{2} \mathrm{Y}_{12}$ receptor is due to its covalent binding to the cysteine sulphydryl residues within the receptor. Although it is well established that clopidogrel is effective in providing significant protection against thrombotic episodes when administered in combination with ASA (Fox et al., 2004), clopidogrel does have some drawbacks. Its onset of action is relatively slow following initiation of standard dosing, and inhibitory effects on platelet function may be highly variable. A major contributing factor to clopidogrel's variable response is the polymorphism of the requisite CYP450 isoenzyme, CYP2C19, that is required for its conversion from prodrug to active drug. Furthermore, gender, ethnicity, body mass index, polymorphism in paraoxnase-1, and comorbidities, such as liver disease and insulin resistance, can significantly affect clopidogrel efficacy.

High on-clopidogrel platelet reactivity or poor responder to clopidogrel, especially due to the described factors above, has been shown to be an important predictor of adverse thrombotic outcomes. Thus, prasugrel (trade name Effient), a newer irreversible agent and third generation thienopyridine, has been developed to accommodate patients with high on-clopidogrel platelet reactivity. Prasugrel has a higher bioavailability profile compared with clopidogrel, resulting in faster onset of action, enhanced platelet inhibition, and lower interindividual variability of platelet response. Based on the TRITON-TIMI 38 clinical trial, prasugrel was shown to significantly reduce the primary efficacy end point (composite cardiovascular deaths, nonfatal myocardial infarction (MI), or nonfatal stroke) in patients with moderate- to high-risk acute coronary syndrome (ACS) undergoing PCI by 19\% compared with clopidogrel over a medium follow-up of 14.5 months (Wiviott et al., 2007). Overall, due to significant bleeding risk in prasugrel compared with clopidogrel, its use is restricted to patients who are less than 75 years old and exceed a body weight of $60 \mathrm{~kg}$.

Ticagrelor (trade names Brilinta, Brilique, Possia), which belongs to the cyclopentyl-triazolo-pyrimidine class, was the first oral allosteric and reversible inhibitor of the $\mathrm{P}_{2} \mathrm{Y}_{12}$ receptor and was approved for use to prevent thrombotic events in patients with ACS or MI with ST elevation. Unlike the thienopyridines, ticagrelor does not require metabolic conversion; however, it can be metabolized to AR-C124910XX by CYP3A4. Its rapid on-rate of platelet inhibition is due to its quick absorption following oral administration. Ticagrelor shows a higher consistent and more predictable level of platelet inhibition compared with clopidogrel. Although ticagrelor is reversible, its off-rate is quite slow, by which $20 \%$ of platelet inhibition still remains 3 days after administration. Ticagralor's slow off-rate is thought to be due to its binding to circulating plasma proteins, which lowers its rate of clearance. According to the PLATO clinical trial, ticagrelor was shown to be more efficacious than clopidogrel and reduced primary endpoint (composite of cardiovascular death, nonfatal MI, and stroke) in ACS patients (James et al., 2009; Wallentin et al., 2009).

Whereas ticagrelor is deemed to be more preferable than clopidogrel, absorption of oral P2Y $\mathrm{Y}_{12}$ inhibitors prior to PCI is still an issue. Thus, an i.v. and reversible formulation, cangrelor (trade name Kengreal in the United States and Kangrexal in Europe) was developed to expedite platelet inhibition. Cangrelor is a reversible $\mathrm{P}_{2} \mathrm{Y}_{12}$ platelet inhibitor that blocks ADP-mediated platelet activation and is currently FDA approved as an adjunct to PCI for reducing the risk of periprocedural MI, stent thrombosis, and repeat coronary revascularization (Franchi et al., 2017) in patients who have not been treated with other $\mathrm{P}_{2} \mathrm{Y}_{12}$ inhibitors or glycosylphosphatidylinositols (GPIs). Like ticagrelor, it has a chemical structure that resembles ATP and does not require metabolic conversion by CYP450 to become active. The half-life of cangrelor is very short (3-5 minutes), and its inhibitory effects on platelet function disappear within minutes following infusion (Storey et al., 2001; Sible and Nawarskas, 2017).

\section{Integrin $\alpha_{I I b} \beta_{3}$ Receptor Inhibitors}

Receptor $\alpha_{\mathrm{IIb}} \beta_{3}$ is targeted by a class of inhibitors categorized into small (tirofiban, eptifibatide) and nonsmall (abciximab) molecules. These molecules exert their antithrombotic effects by preventing the binding of fibrinogen to the most abundant glycoprotein on the platelet surface $(60,000-80,000$ copies per platelet) (Wagner et al., 1996), $\alpha_{\mathrm{IIb}} \beta_{3}$, thereby blocking platelet aggregation. According to the guidelines of American College of Cardiology/American Heart Association, $\alpha_{\mathrm{IIb}} \beta_{3}$ inhibitors are recommended for patients with unstable angina/non-ST elevation myocardial infarction (UA/NSTEMI) who cannot tolerate clopidogrel and are undergoing PCI (Jneid et al., 2012; Amsterdam et al., 2014b). The most serious complications of the GPIs are bleeding and thrombocytopenia. Thrombocytopenia typically occurs within 24 hours of i.v. administration; thus, platelet counts are frequently monitored following infusion.

Abciximab (trade name ReoPro), a recombinant monoclonal antibody recognizing the epitope of the $\beta_{3}$ motif, was the first $\alpha_{\mathrm{II}} \beta_{3}$ inhibitor to be approved by the FDA for use in the clinic for PCI. Clinical trials (EPIC, EPILOG, EPISTENT) have shown that abciximab treatment reduced all-cause mortality by approximately $20 \%$ during long-term follow-up after PCI. The Fab fragment of abciximab was also found to cross-react with $\alpha_{\mathrm{V}} \beta_{3}$ and $\alpha_{\mathrm{M}} \beta_{2}$ (Mac-1, CD11b/CD18), which are expressed by endothelial, smooth muscle cells, and 
leukocytes, respectively. Due to its cross-reactivity, which may be responsible for its unique anti-inflammatory properties, abciximab may provide additional benefits compared with the other GPIs. Abciximab has a slow offrate because it remains bound to the platelets for an extended time (12-24 hours) and may dissociate and reassociate with new platelets for as long as 21 days after cessation of the agent (Kereiakes et al., 2000).

Unlike abciximab, eptifibatide (trade name Integrilin) and tirofiban (trade name Aggrostat) are smaller molecules with a lesser degree of affinity for the receptor and shorter duration of action. Tirofiban is a synthetic nonpeptide tyrosine derivative that acts as a RGD (arginineglycine-aspartic acid) mimetic that has a plasma half-life of 1.5-2 hours and a short biologic half-life, which reflects its reversible and relatively low-binding affinity. After cessation of tirofiban, partial platelet function is recovered within 4 hours. Comparative studies have shown that abciximab and eptifibatide were more effective than tirofiban in inhibiting platelet aggregation (Topol et al., 2001). Interestingly, whereas the TARGET clinical trial also showed abciximab was more effective than the standard dose of tirofiban in preventing ischemic events (Herrmann et al., 2002), a subsequent clinical trial (ADVANCE) suggested that tirofiban was not inferior to abciximab when given at a higher dose (Schneider et al., 2003; Valgimigli et al., 2008).

Eptifibatide, a cyclic heptapeptide, has been shown to rapidly inhibit platelet aggregation, attaining maximal effect within 15 minutes after its bolus injection and maintaining its potent inhibition during infusion. Whereas epitfibatide has a long plasma half-life of $\sim 2.5$ hours, the platelet-bound half-life is short (seconds). Eptifibatide is a reversible inhibitor, as observed by platelet function returning to normal function within 4-8 hours following cessation of drug. Both PURSUIT and ESPRIT clinical trials have shown the efficacy of eptifibatide at higher doses in reducing mortality by 25\%-35\% with a modest increase in bleeding compared with the placebo-treated group (Harrington, 1997; ESPRIT Investigators: Enhanced Suppression of the Platelet IIb/IIIa Receptor with Integrilin Therapy, 2000; Lincoff et al., 2000; O'Shea et al., 2001; O'Shea and Tcheng, 2001). Importantly, eptifibatide is currently the most widely used of the $\alpha_{\mathrm{IIb}} \beta_{3}$ inhibitors for ACS patients in PCI, coronary stents, and UA/NSTEMI pre-PCI, and for medical stabilization of UA/NSTEMI.

\section{Collagen Receptor Inhibitors}

GPVI-Fc (tradename Revacept) is a recombinant GPVI mimetic by which a fusion protein was formed between the extracellular collagen-binding domain of GPVI and the C-terminal of human Ig Fc domain to form a soluble GPVI. The GPVI-Fc predominantly targets the collagen found on the exposed subendothelial ECM at the injured vascular site and prevents the ability of platelet GPVI to bind to the exposed subendothelial ECM. Preclinical studies have successfully proven that injection of GPVI-Fc improved endothelial dysfunction and vascular in atherosclerotic rabbits (Ungerer et al., 2013) as well as reduced arterial thrombus formation, cerebral infarct size, and edema after stroke (Goebel et al., 2013), with improved functional and prognostic outcome with intracranial bleeding. A phase I clinical trial shows infused GPVI-Fc $(10,20,40,80$, or $160 \mathrm{mg}$ ) doses efficiently inhibit collagen-induced platelet aggregation with no alteration in primary hemostasis compared with predosing. Both tumor necrosis factorrelated activation protein- and ADP-induced platelet aggregation were not affected by GPVI-Fc treatment. Revacept could still be detected 3 days after administration of the $10 \mathrm{mg}$ and higher doses, indicating drug elimination is slow. The terminal half-life of the lower doses (10 and $20 \mathrm{mg}$ ) was lower than in the groups receiving higher doses (40, 80, and $160 \mathrm{mg}$ ) (Ungerer et al., 2011). Platelet inhibition occurred at least 2 hours after infusion of Revacept, and the inhibitory effects remained up to 24 hours after infusion of higher doses (40, 80, and $160 \mathrm{mg}$ ). Ten and twenty milligrams Revacept weakly inhibited collagen-induced platelet aggregation 7 days after drug administration, whereas higher doses of Revacept prolonged inhibition of collagen-mediated platelet aggregation at later time points. These data support the safety and efficacy of Revacept in people, but have yet to be verified in patients with ACS. A phase II clinical trial is currently investigating Revacept in stable coronary artery disease patients scheduled for PCI. A composite of death and/or MI injury will be assessed as the primary endpoint in this ongoing trial.

\section{E. Thrombin Receptor Inhibitors}

Thrombin is a potent agonist that not only activates platelets through the proteolytic cleavage of thrombin receptors PAR1 and PAR4, but also plays a key role in the coagulation cascade, which is essential for hemostasis. An appeal to targeting PARs is that thrombin is the most potent agonist, and therefore blocking PAR activation would also block the release of secondary mediators ( $\mathrm{ADP}$ and $\mathrm{TxA}_{2}$ ) from activated platelets. In addition, targeting PARs would avoid directly interfering with thrombin-induced fibrin production involved in hemostatic plug formation. Thus, inhibiting PAR1- or PAR4-induced platelet activation while leaving the other functions of thrombin intact may mitigate the risk of bleeding and provide a more selective effect for prevention of arterial thrombosis.

One of the first PAR antagonists, atopaxar, a smallmolecule and reversible inhibitor of PAR1, derived from bicyclic amidine, was shown to competitively bind at or near the tethered ligand binding site within the second extracellular loop of the receptor. In a guinea pig model of photochemically induced thrombosis, orally administered atopaxar $(30 \mathrm{mg} / \mathrm{kg})$ prolonged the time to vessel occlusion by approximately 2 hours compared with control. The pharmacokinetic assessment showed that 
atopaxar was metabolized by CYP3A4, and the onset of action occurred after 3.5 hours. However, the agent exhibited a slow rate of elimination with a half-life of 23 hours. A phase I study demonstrated that a single dose of 50, 100, and $200 \mathrm{mg}$ drug significantly reduced thrombininduced platelet aggregation with no severe adverse events reported. Two clinical trials (LANCELOT-ACS and LANCELOT-CAD) were conducted to assess the safety of atopaxar in ACS and chronic coronary artery disease. These trials showed relevant bleeding increased numerically but not significantly in the ACS trial; however, the bleeding rates increased in the $\mathrm{CAD}$ trial. Adverse events, such as liver function abnormalities and QT interval prolongation, were observed with higher doses ( $\geq 200 \mathrm{mg}$ ) of atopaxar administration. Currently, there are no phase 3 trials registered to further investigate atopaxar.

Vorapaxpar (trade name Zontivity), a synthetic tricyclic 3-phenylpyridine derived from himbacine, has been FDA and EMA approved for the reduction of thrombotic cardiovascular events in patients with previous MI or peripheral arterial disease (Déry et al., 2016). Vorapaxar is a reversible, competitive antagonist of PAR1 that binds at or near the tethered ligand binding site within the second extracellular loop of PAR1 (Kosoglou et al., 2012) with an estimated Kd of $1.2 \pm 0.3 \mathrm{nM}$ (Hawes et al., 2015). Preclinical studies show vorapaxar can successfully block thrombin- and PAR1-induced human platelet aggregation with an $\mathrm{IC}_{50}$ of 47 and $25 \mathrm{nM}$. Additionally, vorapaxar is shown to have a high oral bioavailability pharmacokinetic profile by which its onset of action occurs 1-2 hours after oral ingestion (5-40 mg) and has a terminal plasma halflife of 125-269 hours. Platelets from healthy subjects orally administered with a single loading dose of vorapaxar ranging from 5 to $40 \mathrm{mg}$ showed PAR1-induced inhibition greater than $90 \%$ for more than 72 hours following administration of the drug (Becker et al., 2009).

Vorapaxar was assessed for efficacy and safety in two large phase 3 clinical trials that included more than 40,000 patients enrolled with ACS (TRACER clinical trial) and stable atherosclerosis (TRA $2^{\circ} \mathrm{P}$-TIMI 50 clinical trial). The TRACER trial concluded that vorapaxar in combination with the standard antiplatelet therapy provided no significant net clinical benefit in patients with ACS, but significantly increased the risk of major bleeding, most notably intracranial hemorrhage in a subset of patients. This was most apparent in patients with prior history of stroke or transient ischemic attack (TIA), by which bleeding was observed to increase incrementally over time, leading to early termination of the TRACER trial. TRA $2^{\circ}$ P-TIMI 50 clinical trial was then modified to enroll patients with stable atherosclerosis and a history of $\mathrm{MI}$ or ischemic stroke (between 2 and 12 months before enrollment) and/or peripheral arterial disease (PAD) (either after revascularization or with an ankle-brachial index of $<0.085$ ), but excluded subset of patients with bleeding risk (history of stroke or TIA) described in TRACER. Unlike TRACER, TRA $2^{\circ} \mathrm{P}$-TIMI 50 excluded the $40 \mathrm{mg}$ single loading dose, but maintained the daily dose of $2.5 \mathrm{mg}$. Both the primary (composite of cardiovascular death, MI, or stroke) and secondary (composite of cardiovascular death, MI, stroke, or urgent revascularization) endpoints TRA $2^{\circ} \mathrm{P}-\mathrm{TIMI}$ 50 were reduced compared with the placebo group; however, as observed in TRACER, bleeding complications were increased in patients receiving vorapaxar. As a result of these trials, the FDA approved vorapaxar for the prevention of thrombotic cardiovascular events in patients with a history of MI or PAD.

In light of the bleeding complications due to PAR1 inhibition, PAR4 antagonism has also been developed as a potential antiplatelet therapeutic avenue. There are several lines of evidence that suggest targeting PAR4 may also protect against occlusive thrombus formation without interfering hemostasis. For instance, PAR1 and PAR4 signal with different kinetics in human platelet activation, and these differences are thought to contribute to different phases of platelet activation. PAR1-induced activation by low thrombin is thought to contribute to the initial phase of platelet activation involved in hemostasis, whereas later stages of platelet activation mediated by the low-affinity thrombin receptor, PAR4, are thought to be important for occlusive thrombosis. PAR4 activation also induces platelet spreading, contributing to the irreversible formation of a stable thrombus. Therefore, targeting PAR4 while preserving PAR1 signaling may selectively inhibit thrombosis without altering hemostasis.

Anti-PAR4 antibodies were used to validate the efficacy and safety of PAR4 inhibition and were shown to restore carotid blood flow following iron (III) chloride (FeCl3)induced thrombotic injury compared with the control IgG antibodies. Importantly, anti-PAR4 antibodies did not significantly prolong bleed times in the guinea pig cuticleand renal-provoked bleeding time models (Wong et al., 2017). These data demonstrated the efficacy and low bleeding liability of PAR4 antagonism, prompting the development of the first, orally bioavailable, small-molecule inhibitor, BMS-986120. BMS-986120 was assessed in a randomized, blinded, placebo-controlled study in healthy cynomolgus monkeys, demonstrating its efficacy in reducing thrombus weight by $83 \%$ at $1 \mathrm{mg} / \mathrm{kg}$ with a twofold increase in bleeding time. In contrast, $0.3 \mathrm{mg} / \mathrm{kg}$ clopidogrel-administered monkeys showed a $48 \%$ reduction in thrombus weight, but with a seven- to eightfold increase in bleeding times (Wong et al., 2017). Recently, the completed phase I PROBE clinical trial showed BMS986120 to exhibit high oral bioavailability in healthy human participants (Wilson et al., 2018). The preclinical and phase I trials have successfully shown the efficacy and limited bleeding risk in reducing thrombosis in healthy animals and volunteers, but these findings have yet to be confirmed in patients at risk for thrombosis.

\section{F. Glycoprotein Ib-IX-V Inhibitors}

Anfibatide (also known as agkicetin) is a C-type lectinlike protein derived from the venom of Agkistrodon 
acutus (Chen and Tsai, 1995), which competitively binds to the region of GPIb $\alpha$ that recognizes the A1 domain of $\mathrm{vWF}$ and prevents GPIb $\alpha$-dependent platelet adhesion and activation under high arterial shear rates (Lei et al., 2014). Preclinical studies were able to demonstrate anfibatide as a potent and safe antithrombotic agent in inhibiting platelet adhesion and thrombus formation in vitro as well as in vivo models of thrombosis. Additionally, anfibatide was shown to improve ischemic stroke model induced by middle cerebral artery occlusion in mice. Importantly, anfibatide-treated mice showed lower incidence of intracerebral hemorrhage and shorter tail bleeding time compared with the tirofibantreated mice ( $\mathrm{Li}$ et al., 2015). Interestingly, the utility of anfibatide has also been evaluated in preventing a fatal blood-clotting disorder, such as TTP. Intraperitoneal administration of anfibatide mitigated spontaneous thrombocytopenia and prevented a shigatoxin-induced TTP murine model (Zheng et al., 2016) (ADAMTS13-deficient mice). Although anfibatide has completed its clinical phase I for safety and efficacy in patients with non-ST elevation myocardial infarction, phase II has yet to commence.

\section{G. IP Receptor Inhibitors}

Prostacyclin derivatives ( $\mathrm{PGI}_{2}$, iloprost, treprostinil) are currently indicated for pulmonary arterial hypertension (PAH) only. The pathophysiology of $\mathrm{PAH}$ is a complex interplay of vasoconstriction, vascular wall hypertrophy, fibrosis, and platelet-associated thrombosis. These effects are mediated by their action on the cognate $\mathrm{G} \alpha_{\mathrm{s}}$-coupled prostacyclin receptor, IP, which is found in endothelial cells, leukocytes, and platelets. One of the first prostacyclin therapies, $\mathrm{PGI}_{2}$ (trade name Epoprostenol), had been shown to be a potent vasodilator, inhibitor of platelet function, inflammation, and smooth muscle proliferation. Due to $\mathrm{PGI}_{2}$ short plasma half-life of 6 minutes, which presents clinical challenges, continuous infusion is needed to improve outcome. Because of the chemical instability, $\mathrm{PGI}_{2}$ was deemed not an ideal therapy for treatment of arterial thrombotic-associated conditions. A slightly longer half-life prostacyclin derivative, iloprost (trade name Ventavis), was also developed for $\mathrm{PAH}$, but administered via oral inhalation. Antagonism of platelet function via $\mathrm{G} \alpha_{\mathrm{s}}$ activation is well established to prevent platelet activation and thrombosis. To confirm this effect, iloprost was infused into patients with peripheral vascular disease and monitored for platelet reactivity. Unfortunately, iloprost infusion enhanced blood coagulation and platelet reactivity, representing a risk for thromboembolism (Kovacs et al., 1991) in some patients. Thus, iloprost is contraindicated in patients who are already in prethrombotic conditions. Similar to $\mathrm{PGI}_{2}$, iloprost is found to have a short plasma half-life and observed to be completely metabolized to compounds that are excreted primarily in the urine.

To achieve a longer half-life profile for targeting the IP receptor, treprostinil was developed. Its multiple administration formulation include inhaled (trade name Tyvaso), i.v. (trade name Remodulin), and oral (trade name Orenitram). Interestingly, treprostinil not only binds to IP receptor, but is also found to activate peroxisome proliferator-activated receptor $\gamma$. Side effects (flushing, hypotension, nausea, jaw pain, cough, headache, and diarrhea) are commonly associated with prostacyclin derivatives. Due to the lack of selectivity and side effects, beraprost, a stable synthetic prostacyclin analog, is currently undergoing clinical investigation for $\mathrm{PAH}$. Beraprost sodium (BPS) has been monitored for its potential treatment of acute ischemic stroke in combination with ASA; however, BPS and ASA were not observed to significantly reduce the recurrence of cerebral infarction or death compared with ASA alone. Incidence of bleeding risk for BPS- and ASA-treated group was similar to ASA alone. Thus, BPS plus ASA was not found to be superior to ASA alone in the overall improvement or survival of acute ischemic stroke events (Chen et al., 2017). To date, the current prostacyclin derivatives (epoprostenol, treprostinil, and iloprost) are FDA approved for the treatment of $\mathrm{PAH}$ only. The existing IP selectivity challenges of the current or ongoing investigational prostacyclin analogs emphasize a clear need for improved targeted drug design.

\section{H. Phosphodiesterase Inhibitors}

Elevation of platelet cyclic nucleotides, cAMP and cGMP, results in the activation of protein kinases that phosphorylate a number of substrates, including myosin light chain kinase and vasodilator-stimulated phosphoprotein. As a consequence of cAMP or cGMP increase, cytoskeletal rearrangement and fibrinogen receptor activation are inhibited, preventing platelet activation. Because platelets express three PDE isoenzymes, PDE2, PDE3, and PDE5, this section will focus on selective PDE inhibitors that are in the clinic to regulate platelet function involved in thrombotic-related diseases.

One of the earlier PDE inhibitors, dipyridamole, was found to inhibit PDE5 and PDE3, resulting in the elevation of intracellular cAMP and cGMP. In addition, dipyridamole exhibited antioxidant activity by which it reduced the superoxide anion that inactivates $\mathrm{COX}$, and thereby increased $\mathrm{PGI}_{2}$ synthesis. The ESPS2 and ESPRIT clinical trials established dipyridamole in combination with low-dose ASA is associated with greater stroke reduction in patients with ischemic cerebrovascular disease (Diener et al., 1996, 2001; Halkes et al., 2006, 2008). However, when dipyridamole was given alone or in combination with another antiplatelet agent, there was no evidence that dipyridamole reduced risk of vascular death in patient with arterial disease compared with placebo (De Schryver et al., 2007). Based on these earlier findings, dipyridamole has been FDA approved in combination with ASA for the secondary prevention of stroke.

Cilostazol (trade name Pletal) is a member of phosphodiesterase III (PDE3) drug class that raises cAMP to inhibit platelet activation as well as inducing vasodilation. Cilostazol is also shown to inhibit adenosine uptake, 
thus enhancing adenosine levels, which in turn raises intracellular cAMP. Currently, cilostazol is indicated as a first-line therapy to treat the symptoms of intermittent claudication in patients with $\mathrm{PAD}$, but contraindicated in patients with heart failure due to common adverse effects (tachycardia, palpitations, diarrhea, soft stools, and headache). Clinical trials have demonstrated that cilostazol is rapidly absorbed and primarily metabolized by CYP3A5 and to a lesser extent, CYP2C19, into its active metabolites, dehydrocilostazol (OPC-13015) and monohydroxycilostazol (OPC-13213), respectively (Yoo et al., 2010), reaching averaged peak concentration of $775 \mathrm{ng} / \mathrm{ml}$ or $2.09 \mu \mathrm{M}$ at about 2.5 hours with a half-life of approximately 10 hours. Because of the CYP3A5 and CYP2C19 polymorphisms, there is considerable interindividual variation in cilostazol pharmacokinetic parameters (Yoo et al., 2009) as well as platelet response following administration.

Clinical studies have demonstrated the efficacy and bleeding safety of cilostazol coadministered with clopidogrel and ASA in ACS patients undergoing PCI (Jeong et al., 2010) by which they reduced the composite endpoint of cardiac death, MI, and stroke in comparison with ASA plus clopidogrel therapy (Suh et al., 2011). The CSPS 1 clinical trial also showed that cilostazol significantly reduced the recurrence of ischemic stroke and the incidence of the combined endpoint of MI, TIA, and intracranial hemorrhage without a significant increase of bleeding and fatal intracranial hemorrhage. In the second CSPS 2 trial, patients with noncardioembolic cerebral infarction within the previous 26 weeks were orally administered with $100 \mathrm{mg}$ cilostazol twice daily and showed noninferiority or possibly superiority to $81 \mathrm{mg}$ ASA once daily in preventing recurrence of stroke and cilostazol was associated with fewer bleeding events. In addition, restenosis tended to be lower with cilostazol, but not significant compared with patients with ticlopidine and ASA in patients undergoing elective coronary stenting. Another small study showed cilostazol administration improved long-term patency after carotid artery stenting in 97 patients with high-grade carotid stenosis monitored for 12 months. In conclusion, several of these clinical trial findings with cilostazol, alone or in combination with other antiplatelet drugs, do show efficacy with limited bleeding risk, but further clinical research would need to be conducted in the United States for the approval of its use for other thrombotic diseases.

\section{Conclusions}

Platelets play a critical role in maintaining blood in circulation and are often thought of as the key regulators of hemostasis and thrombosis. This review describes some of the recent work in the field that has elucidated the diversity of roles regulated by the platelet in addition to its role in hemostasis. To regulate the level of platelet activation in the vessel, a number of pharmacological targets have been identified and are currently being used in the clinic. Although inhibition of platelets can now be achieved through traditional interventional approaches, this has led to a significant increase in pathologic bleeding. The current review therefore has given an overview not only of the approved targets for pharmacological intervention in the platelet, but additionally describes the newly identified pharmacological targets in the platelet and how they are being developed as drugs to limit platelet activation and thrombosis while sparing the concomitant bleeding. Development of these targets is essential to attain better control over the numerous functions regulated by the platelet.

\section{Authorship Contributions}

Wrote or contributed to the writing of the manuscript: Yeung, Li, Holinstat.

\section{References}

Abramovitz M, Adam M, Boie Y, Carrière M, Denis D, Godbout C, Lamontagne S, Rochette C, Sawyer N, Tremblay NM, et al. (2000) The utilization of recombinant prostanoid receptors to determine the affinities and selectivities of prostaglandins and related analogs. Biochim Biophys Acta 1483:285-293.

Adili R, Tourdot BE, Mast K, Yeung J, Freedman JC, Green A, Luci DK, Jadhav A Simeonov A, Maloney DJ, et al. (2017) First selective 12-LOX inhibitor, ML355, impairs thrombus formation and vessel occlusion in vivo with minimal effects on hemostasis. Arterioscler Thromb Vasc Biol 37:1828-1839.

Altman R, Luciardi HL, Muntaner J, and Herrera RN (2004) The antithrombotic profile of aspirin: aspirin resistance, or simply failure? Thromb $J$ 2:1

Amsterdam EA, Wenger NK, Brindis RG, Casey DE Jr, Ganiats TG, Holmes DR Jr, Jaffe AS, Jneid H, Kelly RF, Kontos MC, et al. ACC/AHA Task Force Members (2014a) 2014 AHA/ACC guideline for the management of patients with nonST-elevation acute coronary syndromes: a report of the American College of Cardiology/American Heart Association Task Force on Practice Guidelines [published correction appears in Circulation (2014) 130:e433-e434]. Circulation 130: e344-e426.

Amsterdam EA, Wenger NK, Brindis RG, Casey DE Jr, Ganiats TG, Holmes DR Jr, Jaffe AS, Jneid H, Kelly RF, Kontos MC, et al. ACC/AHA Task Force Members; Society for Cardiovascular Angiography and Interventions and the Society of Thoracic Surgeons (2014b) 2014 AHA/ACC guideline for the management of patients with non-ST-elevation acute coronary syndromes: executive summary: a report of the American College of Cardiology/American Heart Association Task Force on Practice Guidelines [published correction appears in Circulation (2014) 130:e431-e432]. Circulation 130:2354-2394.

Appiani AC, Edefonti A, Bettinelli A, Cossu MM, Paracchini ML, and Rossi E (1982) The relationship between plasma levels of the factor VIII complex and platelet release products (beta-thromboglobulin and platelet factor 4) in children with the hemolytic-uremic syndrome. Clin Nephrol 17:195-199.

Arachiche A, Mumaw MM, de la Fuente M, and Nieman MT (2013) Proteaseactivated receptor 1 (PAR1) and PAR4 heterodimers are required for PAR1enhanced cleavage of PAR4 by $\alpha$-thrombin. J Biol Chem 288:32553-32562.

Arachiche A and Nieman MT (2017) The platelet PARs, in Platelets in Thrombotic and Non-Thrombotic Disorders: Pathophysiology, Pharmacology and Therapeutics: An Update, pp 171-185, Springer International Publishing, Cham, Switzerland. Arman M, Krauel K, Tilley DO, Weber C, Cox D, Greinacher A, Kerrigan SW, and Watson SP (2014) Amplification of bacteria-induced platelet activation is triggered by Fc $\gamma$ RIIA, integrin $\alpha I I b \beta 3$, and platelet factor 4. Blood 123:3166-3174.

Arroyo JG, Dastgheib K, and Hatchell DL (2001) Antithrombotic effect of ticlopidine in an experimental model of retinal vein occlusion. Jpn J Ophthalmol 45:359-362. Assinger A (2014) Platelets and infection - an emerging role of platelets in viral infection. Front Immunol 5:649.

Assinger A, Kral JB, Yaiw KC, Schrottmaier WC, Kurzejamska E, Wang Y, Mohammad AA, Religa P, Rahbar A, Schabbauer G, et al. (2014) Human cytomegalovirus-platelet interaction triggers Toll-like receptor 2-dependent proinflammatory and proangiogenic responses. Arterioscler Thromb Vasc Biol 34:801-809.

Assoian RK, Komoriya A, Meyers CA, Miller DM, and Sporn MB (1983) Transforming growth factor-beta in human platelets: identification of a major storage site, purification, and characterization. J Biol Chem 258:7155-7160.

Ay C, Freyssinet JM, Sailer T, Vormittag R, and Pabinger I (2009) Circulating procoagulant microparticles in patients with venous thromboembolism. Thromb Res 123:724-726.

Ayyanathan K, Webbs TE, Sandhu AK, Athwal RS, Barnard EA, and Kunapuli SP (1996) Cloning and chromosomal localization of the human P2Y1 purinoceptor. Biochem Biophys Res Commun 218:783-788.

Badolia R, Inamdar V, Manne BK, Dangelmaier C, Eble JA, and Kunapuli SP (2017) $\mathrm{G}_{\mathrm{q}}$ pathway regulates proximal C-type lectin-like receptor-2 (CLEC-2) signaling in platelets. J Biol Chem 292:14516-14531.

Becattini C, Agnelli G, Schenone A, Eichinger S, Bucherini E, Silingardi M, Bianchi M, Moia M, Ageno W, Vandelli MR, et al.; WARFASA Investigators (2012) Aspirin for preventing the recurrence of venous thromboembolism. N Engl J Med 366: 1959-1967. 
Becker RC, Moliterno DJ, Jennings LK, Pieper KS, Pei J, Niederman A, Ziada KM, Berman G, Strony J, Joseph D, et al.; TRA-PCI Investigators (2009) Safety and tolerability of SCH 530348 in patients undergoing non-urgent percutaneous coronary intervention: a randomised, double-blind, placebo-controlled phase II study. Lancet 373:919-928.

Bergmeier W and Stefanini L (2013) Platelet ITAM signaling. Curr Opin Hematol 20: $445-450$.

Bernat A and Herbert JM (1994) Effect of various drugs on adriamycin-enhanced venous thrombosis in the rat: importance of PAF. Thromb Res 75:91-97.

Best MG, Sol N, Kooi I, Tannous J, Westerman BA, Rustenburg F, Schellen P, Verschueren H, Post E, Koster J, et al. (2015) RNA-seq of tumor-educated platelets enables blood-based pan-cancer, multiclass, and molecular pathway cancer diagnostics. Cancer Cell 28:666-676.

Bird JE, Wang X, Smith PL, Barbera F, Huang C, and Schumacher WA (2012) A platelet target for venous thrombosis? P2Y1 deletion or antagonism protects mice from vena cava thrombosis. $J$ Thromb Thrombolysis 34:199-207.

Boilard E, Duchez AC, and Brisson A (2015) The diversity of platelet microparticles. Curr Opin Hematol 22:437-444.

Boilard E, Nigrovic PA, Larabee K, Watts GF, Coblyn JS, Weinblatt ME, Massarotti EM, Remold-O'Donnell E, Farndale RW, Ware J, et al. (2010) Platelets amplify inflammation in arthritis via collagen-dependent microparticle production. Science 327:580-583.

Boilard E, Paré G, Rousseau M, Cloutier N, Dubuc I, Lévesque T, Borgeat P, and Flamand L (2014) Influenza virus H1N1 activates platelets through FcyRIIA signaling and thrombin generation. Blood 123:2854-2863.

Brighton TA, Eikelboom JW, Mann K, Mister R, Gallus A, Ockelford P, Gibbs H, Hague W, Xavier D, Diaz R, et al.; ASPIRE Investigators (2012) Low-dose aspirin for preventing recurrent venous thromboembolism. N Engl J Med 367:1979-1987.

Calzada C, Vericel E, and Lagarde M (1997) Low concentrations of lipid hydroperoxides prime human platelet aggregation specifically via cyclo-oxygenase activation. Biochem $J$ 325:495-500.

Capodanno D and Angiolillo DJ (2016) Aspirin for primary cardiovascular risk prevention and beyond in diabetes mellitus. Circulation 134:1579-1594.

Capodanno D, Ferreiro JL, and Angiolillo DJ (2013) Antiplatelet therapy: new pharmacological agents and changing paradigms. J Thromb Haemost 11 (Suppl 1): 316-329.

Capone ML, Tacconelli S, Rodriguez LG, and Patrignani P (2010) NSAIDs and cardiovascular disease: transducing human pharmacology results into clinical readouts in the general population. Pharmacol Rep 62:530-535.

Chandrasekharan JA, Marginean A, and Sharma-Walia N (2016) An insight into the role of arachidonic acid derived lipid mediators in virus associated pathogenesis and malignancies. Prostaglandins Other Lipid Mediat 126:46-54.

Chang J, Blazek E, Kreft AF, and Lewis AJ (1985) Inhibition of platelet and neutrophil phospholipase A2 by hydroxyeicosatetraenoic acids (HETES): a novel pharmacological mechanism for regulating free fatty acid release. Biochem Pharmacol 34:1571-1575.

Chen S, Xie S, He W, Wei D, Li S, and Chen W (2017) Beneficial effect of beraprost sodium plus aspirin in the treatment of acute ischemic stroke. Med Sci Monit $\mathbf{2 3}$ 4401-4407.

Chen WF, Lee JJ, Chang CC, Lin KH, Wang SH, and Sheu JR (2013) Platelet protease-activated receptor (PAR)4, but not PAR1, associated with neutral sphingomyelinase responsible for thrombin-stimulated ceramide-NF-кB signaling in human platelets. Haematologica 98:793-801.

Chen YL and Tsai IH (1995) Functional and sequence characterization of agkicetin, a new glycoprotein Ib antagonist isolated from Agkistrodon acutus venom. offf2p4. Biochem Biophys Res Commun 210:472-477.

Cheng Y, Austin SC, Rocca B, Koller BH, Coffman TM, Grosser T, Lawson JA, and FitzGerald GA (2002) Role of prostacyclin in the cardiovascular response to thromboxane A2. Science 296:539-541.

Cheung PP, Xu H, McLaughlin MM, Ghazaleh FA, Livi GP, and Colman RW (1996) Human platelet cGI-PDE: expression in yeast and localization of the catalytic domain by deletion mutagenesis. Blood 88:1321-1329.

Chirinos JA, Heresi GA, Velasquez H, Jy W, Jimenez JJ, Ahn E, Horstman LL, Soriano AO, Zambrano JP, and Ahn YS (2005) Elevation of endothelial microparticles, platelets, and leukocyte activation in patients with venous thromboembolism. J Am Coll Cardiol 45:1467-1471.

Clark SR, Ma AC, Tavener SA, McDonald B, Goodarzi Z, Kelly MM, Patel KD, Chakrabarti S, McAvoy E, Sinclair GD, et al. (2007) Platelet TLR4 activates neutrophi extracellular traps to ensnare bacteria in septic blood. Nat Med 13:463-469.

Clemetson KJ and Clemetson JM (2001) Platelet collagen receptors. Thromb Haemost 86:189-197.

Coller BS and Shattil SJ (2008) The GPIIb/IIIa (integrin alphaIIbbeta3) odyssey: a technology-driven saga of a receptor with twists, turns, and even a bend. Blood 112:3011-3025.

Conti M, Nemoz G, Sette C, and Vicini E (1995) Recent progress in understanding the hormonal regulation of phosphodiesterases. Endocr Rev 16:370-389.

Cosemans JM, Iserbyt BF, Deckmyn H, and Heemskerk JW (2008) Multiple ways to switch platelet integrins on and off. J Thromb Haemost 6:1253-1261.

Covic L, Gresser AL, and Kuliopulos A (2000) Biphasic kinetics of activation and signaling for PAR1 and PAR4 thrombin receptors in platelets. Biochemistry 39: 5458-5467.

Dashevsky O, Varon D, and Brill A (2009) Platelet-derived microparticles promote invasiveness of prostate cancer cells via upregulation of MMP-2 production. Int $J$ Cancer 124:1773-1777.

Degerman E, Belfrage P, and Manganiello VC (1997) Structure, localization, and regulation of cGMP-inhibited phosphodiesterase (PDE3). J Biol Chem 272 $6823-6826$

De Luca G (2012) Glycoprotein IIb-IIIa inhibitors. Cardiovasc Ther 30:e242-e254.

Déry JP, Mahaffey KW, Tricoci P, White HD, Podder M, Westerhout CM, Moliterno

DJ, Harrington RA, Chen E, Strony J, et al. (2016) Arterial access site and outcomes in patients undergoing percutaneous coronary intervention with and without vorapaxar. Catheter Cardiovasc Interv 88:163-173.

De Schryver EL, Algra A, and van Gijn J (2007) Dipyridamole for preventing stroke and other vascular events in patients with vascular disease. Cochrane Database Syst Rev (3):CD001820.

Diacovo TG, deFougerolles AR, Bainton DF, and Springer TA (1994) A functional integrin ligand on the surface of platelets: intercellular adhesion molecule-2. J Clin Invest 94:1243-1251.

Diacovo TG, Puri KD, Warnock RA, Springer TA, and von Andrian UH (1996a) Platelet-mediated lymphocyte delivery to high endothelial venules. Science $\mathbf{2 7 3}$ $252-255$

Diacovo TG, Roth SJ, Buccola JM, Bainton DF, and Springer TA (1996b) Neutrophil rolling, arrest, and transmigration across activated, surface-adherent platelets via sequential action of P-selectin and the beta 2-integrin CD11b/CD18. Blood 88: 146-157.

Diener HC, Cunha L, Forbes C, Sivenius J, Smets P, and Lowenthal A (1996) European Stroke Prevention Study. 2. Dipyridamole and acetylsalicylic acid in the secondary prevention of stroke. J Neurol Sci 143:1-13.

Diener HC, Darius H, Bertrand-Hardy JM, and Humphreys M; European Stroke Prevention Study 2 (2001) Cardiac safety in the European Stroke Prevention Study 2 (ESPS2). Int J Clin Pract 55:162-163.

Dohlman HG, Bouvier M, Benovic JL, Caron MG, and Lefkowitz RJ (1987) The multiple membrane spanning topography of the beta 2-adrenergic receptor: localization of the sites of binding, glycosylation, and regulatory phosphorylation by limited proteolysis. J Biol Chem 262:14282-14288.

Edelstein LC, Simon LM, Lindsay CR, Kong X, Teruel-Montoya R, Tourdot BE, Chen ES, Ma L, Coughlin S, Nieman M, et al. (2014) Common variants in the human platelet PAR4 thrombin receptor alter platelet function and differ by race. Blood 124:3450-3458.

Eikelboom JW, Hirsh J, Spencer FA, Baglin TP, and Weitz JI(2012) Antiplatelet drugs: antithrombotic therapy and prevention of thrombosis, 9th ed: American College of Chest Physicians evidence-based clinical practice guidelines. Chest 141 e89S-e119S

ESPRIT Investigators: Enhanced Suppression of the Platelet IIb/IIIa Receptor with Integrilin Therapy (2000) Novel dosing regimen of eptifibatide in planned coronary stent implantation (ESPRIT): a randomised, placebo-controlled trial. Lancet $\mathbf{3 5 6}$ : 2037-2044.

Faxon DP, Creager MA, Smith SC Jr, Pasternak RC, Olin JW, Bettmann MA, Criqui MH, Milani RV, Loscalzo J, Kaufman JA, et al. American Heart Association (2004) Atherosclerotic vascular disease conference: executive summary: atherosclerotic vascular disease conference proceeding for healthcare professionals from a specia writing group of the American Heart Association. Circulation 109:2595-2604.

Fischer S and Weber PC (1985) Thromboxane (TX)A3 and prostaglandin (PG)I3 are formed in man after dietary eicosapentaenoic acid: identification and quantification by capillary gas chromatography-electron impact mass spectrometry. Biomed Mass Spectrom 12:470-476.

Fitzgerald JR, Foster TJ, and Cox D (2006a) The interaction of bacterial pathogens with platelets. Nat Rev Microbiol 4:445-457.

Fitzgerald JR, Loughman A, Keane F, Brennan M, Knobel M, Higgins J, Visai L, Speziale P, Cox D, and Foster TJ (2006b) Fibronectin-binding proteins of Staphylococcus aureus mediate activation of human platelets via fibrinogen and fibronectin bridges to integrin GPIIb/IIIa and IgG binding to the FcgammaRIIa receptor. Mol Microbiol 59:212-230.

Fonlupt P, Croset M, and Lagarde M (1991) 12-HETE inhibits the binding of PGH2/TXA2 receptor ligands in human platelets. Thromb Res 63:239-248.

Fox KA, Mehta SR, Peters R, Zhao F, Lakkis N, Gersh BJ, and Yusuf S; Clopidogrel in Unstable Angina to Prevent Recurrent Ischemic Events Trial (2004) Benefits and risks of the combination of clopidogrel and aspirin in patients undergoing surgical revascularization for non-ST-elevation acute coronary syndrome: the Clopidogrel in Unstable angina to prevent Recurrent ischemic Events (CURE) Trial. Circulation 110:1202-1208.

Franchi F, Rollini F, and Angiolillo DJ (2017) Antithrombotic therapy for patients with STEMI undergoing primary PCI. Nat Rev Cardiol 14:361-379.

Funk CD, Furci L, and Fitzgerald GA (1990) Molecular cloning of the human platele 12-lipoxygenase. Trans Assoc Am Physicians 103:180-186.

Galli M, Grassi A, and Barbui T (1996) Platelet-derived microvesicles in thrombotic thrombocytopenic purpura and hemolytic uremic syndrome. Thromb Haemost $\mathbf{7 5}$ : 427-431.

Garcia Rodriguez P, Eikenboom HC, Tesselaar ME, Huisman MV, Nijkeuter M, Osanto S, and Bertina RM (2010) Plasma levels of microparticle-associated tissue factor activity in patients with clinically suspected pulmonary embolism. Thromb Res 126:345-349.

Gastpar H (1977) Platelet-cancer cell interaction in metastasis formation: a possible therapeutic approach to metastasis prophylaxis. J Med 8:103-114.

Goebel S, Li Z, Vogelmann J, Holthoff HP, Degen H, Hermann DM, Gawaz M, Ungerer M, and Münch G (2013) The GPVI-Fc fusion protein Revacept improves cerebral infarct volume and functional outcome in stroke. PLoS One 8:e66960.

Gong H, Shen B, Flevaris P, Chow C, Lam SCT, Voyno-Yasenetskaya TA, Kozasa T, and Du X (2010) G protein subunit Galpha13 binds to integrin alphaIIbbeta3 and mediates integrin "outside-in" signaling. Science 327:340-343.

Gregov D, Jenkins A, Duncan E, Siebert D, Rodgers S, Duncan B, Bochner F, and Lloyd J (1987) Dipyridamole: pharmacokinetics and effects on aspects of platelet function in man. Br J Clin Pharmacol 24:425-434.

Grignani G, Pacchiarini L, Ricetti MM, Dionigi P, Jemos V, Zucchella M, and Fratino $\mathrm{P}$ (1989) Mechanisms of platelet activation by cultured human cancer cells and cells freshly isolated from tumor tissues. Invasion Metastasis 9:298-309.

Guillem-Llobat P, Dovizio M, Bruno A, Ricciotti E, Cufino V, Sacco A, Grande R, Alberti S, Arena V, Cirillo M, et al. (2016) Aspirin prevents colorectal cancer metastasis in mice by splitting the crosstalk between platelets and tumor cells. Oncotarget 7:32462-32477. 
Habib A, FitzGerald GA, and Maclouf J (1999) Phosphorylation of the thromboxane receptor alpha, the predominant isoform expressed in human platelets. $J$ Biol Chem 274:2645-2651.

Halkes PH, Gray LJ, Bath PM, Diener HC, Guiraud-Chaumeil B, Yatsu FM, and Algra A (2008) Dipyridamole plus aspirin versus aspirin alone in secondary prevention after TIA or stroke: a meta-analysis by risk. $J$ Neurol Neurosurg Psychiatry 79:1218-1223.

Halkes PH, van Gijn J, Kappelle LJ, Koudstaal PJ, and Algra A; ESPRIT Study Group (2006) Aspirin plus dipyridamole versus aspirin alone after cerebral ischaemia of arterial origin (ESPRIT): randomised controlled trial [published correction appears in Lancet (2007) 369:274]. Lancet 367:1665-1673.

Hamzeh-Cognasse H, Damien P, Chabert A, Pozzetto B, Cognasse F, and Garraud O (2015) Platelets and infections - complex interactions with bacteria. Front Immunol 6:82

Harrington RA (1997) Design and methodology of the PURSUIT trial: evaluating eptifibatide for acute ischemic coronary syndromes: platelet glycoprotein IIb-IIIa in unstable angina: receptor suppression using integrilin therapy. Am J Cardiol 80 : 34B-38B.

Hata AN and Breyer RM (2004) Pharmacology and signaling of prostaglandin receptors: multiple roles in inflammation and immune modulation. Pharmacol Ther 103:147-166

Hawes BE, Zhai Y, Hesk D, Wirth M, Wei H, Chintala M, and Seiffert D (2015) In vitro pharmacological characterization of vorapaxar, a novel platelet thrombin receptor antagonist. Eur J Pharmacol 762:221-228.

Herbert JM, Bernat A, Sainte-Marie M, Dol F, and Rinaldi M (1993) Potentiating effect of clopidogrel and SR 46349, a novel 5-HT2 antagonist, on streptokinaseinduced thrombolysis in the rabbit. Thromb Haemost 69:268-271.

Herrmann HC, Swierkosz TA, Kapoor S, Tardiff DC, DiBattiste PM, Hirshfeld JW, Klugherz BD, Kolansky DM, Magness K, Valettas N, et al. (2002) Comparison of degree of platelet inhibition by abciximab versus tirofiban in patients with unstable angina pectoris and non-Q-wave myocardial infarction undergoing percutaneous coronary intervention. Am J Cardiol 89:1293-1297.

Herzog BH, Fu J, Wilson SJ, Hess PR, Sen A, McDaniel JM, Pan Y, Sheng M, Yago T, Silasi-Mansat R, et al. (2013) Podoplanin maintains high endothelial venule integrity by interacting with platelet CLEC-2. Nature 502:105-109.

Holinstat M (2017) Normal platelet function. Cancer Metastasis Rev 36:195-198.

Holinstat M, Boutaud O, Apopa PL, Vesci J, Bala M, Oates JA, and Hamm HE (2011) Protease-activated receptor signaling in platelets activates cytosolic phospholipase A2 $\alpha$ differently for cyclooxygenase-1 and 12-lipoxygenase catalysis. Arterioscler Thromb Vasc Biol 31:435-442.

Holinstat M, Preininger AM, Milne SB, Hudson WJ, Brown HA, and Hamm HE (2009) Irreversible platelet activation requires protease-activated receptor 1-mediated signaling to phosphatidylinositol phosphates. Mol Pharmacol 76 301-313

Holinstat M and Tourdot BE (2015) Coronary heart disease risk factors take a disproportional toll on women. Arterioscler Thromb Vasc Biol 35:750-751.

Holinstat M, Voss B, Bilodeau ML, and Hamm HE (2007) Protease-activated receptors differentially regulate human platelet activation through a phosphatidic acid-dependent pathway. Mol Pharmacol 71:686-694.

Holinstat M, Voss B, Bilodeau ML, McLaughlin JN, Cleator J, and Hamm HE (2006) PAR4, but not PAR1, signals human platelet aggregation via $\mathrm{Ca} 2+$ mobilization and synergistic P2Y12 receptor activation. J Biol Chem 281:26665-26674.

Hollopeter G, Jantzen HM, Vincent D, Li G, England L, Ramakrishnan V, Yang RB, Nurden P, Nurden A, Julius D, et al. (2001) Identification of the platelet ADP receptor targeted by antithrombotic drugs. Nature 409:202-207.

Huang ES, Strate LL, Ho WW, Lee SS, and Chan AT (2011) Long-term use of aspirin and the risk of gastrointestinal bleeding. Am J Med 124:426-433.

Huang JS, Dong L, Kozasa T, and Le Breton GC (2007) Signaling through G(alpha)13 switch region I is essential for protease-activated receptor 1-mediated human platelet shape change, aggregation, and secretion. J Biol Chem 282:10210-10222.

Hughes CE, Auger JM, McGlade J, Eble JA, Pearce AC, and Watson SP (2008) Differential roles for the adapters Gads and LAT in platelet activation by GPVI and CLEC-2. J Thromb Haemost 6:2152-2159.

Hung DT, Wong YH, Vu TK, and Coughlin SR (1992) The cloned platelet thrombin receptor couples to at least two distinct effectors to stimulate phosphoinositide hydrolysis and inhibit adenylyl cyclase. J Biol Chem 267:20831-20834.

Imbault P, Doutremepuich F, Aguejouf O, and Doutremepuich C (1996) Antithrombotic effects of aspirin and LMWH in a laser-induced model of arterials and venous thrombosis. Thromb Res 82:469-478.

Inoue O, Suzuki-Inoue K, Dean WL, Frampton J, and Watson SP (2003) Integrin alpha2beta1 mediates outside-in regulation of platelet spreading on collagen through activation of Src kinases and PLCgamma2. J Cell Biol 160:769-780.

Italiano JE Jr, Mairuhu AT, and Flaumenhaft R (2010) Clinical relevance of microparticles from platelets and megakaryocytes. Curr Opin Hematol 17:578-584.

Italiano JE Jr, Richardson JL, Patel-Hett S, Battinelli E, Zaslavsky A, Short S, Ryeom S, Folkman J, and Klement GL (2008) Angiogenesis is regulated by a novel mechanism: pro- and antiangiogenic proteins are organized into separate platelet alpha granules and differentially released. Blood 111:1227-1233.

Jackson SP (2011) Arterial thrombosis-insidious, unpredictable and deadly. Nat Med 17:1423-1436.

Jacques SL and Kuliopulos A (2003) Protease-activated receptor-4 uses dual prolines and an anionic retention motif for thrombin recognition and cleavage. Biochem $J$ 376:733-740.

James S, Akerblom A, Cannon CP, Emanuelsson H, Husted S, Katus H, Skene A Steg PG, Storey RF, Harrington R, et al. (2009) Comparison of ticagrelor, the first reversible oral $\mathrm{P} 2 \mathrm{Y}(12)$ receptor antagonist, with clopidogrel in patients with acute coronary syndromes: rationale, design, and baseline characteristics of the PLATelet inhibition and patient Outcomes (PLATO) trial. Am Heart $J \mathbf{1 5 7}$ 599-605.

Jeong YH, Hwang JY, Kim IS, Park Y, Hwang SJ, Lee SW, Kwak CH, and Park SW (2010) Adding cilostazol to dual antiplatelet therapy achieves greater platelet inhibition than high maintenance dose clopidogrel in patients with acute myocardial infarction: results of the adjunctive cilostazol versus high maintenance dose clopidogrel in patients with AMI (ACCEL-AMI) study. Circ Cardiovasc Interv 3: $17-26$

Jneid H, Anderson JL, Wright RS, Adams CD, Bridges CR, Casey JrDE, Ettinger SM, Fesmire FM, Ganiats TG, Lincoff AM, et al. (2012) 2012 ACCF/AHA focused update of the guideline for the management of patients with unstable angina/non-STelevation myocardial infarction (updating the 2007 guideline and replacing the 2011 focused update): a report of the American College of Cardiology Foundation/American Heart Association Task Force on Practice Guidelines. J Am Coll Cardiol 60:645-681.

Judd BA, Myung PS, Obergfell A, Myers EE, Cheng AM, Watson SP, Pear WS, Allman D, Shattil SJ, and Koretzky GA (2002) Differential requirement for LAT and SLP-76 in GPVI versus T cell receptor signaling. $J$ Exp Med 195: $705-717$.

Jung SM and Moroi M (1998) Platelets interact with soluble and insoluble collagens through characteristically different reactions. J Biol Chem 273:14827-14837.

Jurasz P, Alonso-Escolano D, and Radomski MW (2004) Platelet-cancer interactions: mechanisms and pharmacology of tumour cell-induced platelet aggregation. $\mathrm{Br} J$ Pharmacol 143:819-826.

Kaplan JE and Saba TM (1978) Platelet removal from the circulation by the liver and spleen. Am J Physiol 235:H314-H320.

Katayama M, Handa M, Araki Y, Ambo H, Kawai Y, Watanabe K, and Ikeda Y (1993) Soluble P-selectin is present in normal circulation and its plasma level is elevated in patients with thrombotic thrombocytopenic purpura and haemolytic uraemic syndrome. $\mathrm{Br}$ J Haematol 84:702-710.

Kato Y, Kaneko M, Sata M, Fujita N, Tsuruo T, and Osawa M (2005) Enhanced expression of Aggrus (T1alpha/podoplanin), a platelet-aggregation-inducing factor in lung squamous cell carcinoma. Tumour Biol 26:195-200.

Kauffenstein G, Bergmeier W, Eckly A, Ohlmann P, Léon C, Cazenave JP, Nieswandt B, and Gachet C (2001) The P2Y(12) receptor induces platelet aggregation through weak activation of the alpha(IIb)beta(3) integrin-a phosphoinositide 3-kinase-dependent mechanism. FEBS Lett 505:281-290.

Kauskot A and Hoylaerts MF (2012) Platelet receptors, in Antiplatelet Agents. Handbook of Experimental Pharmacology (Gresele P, Born G, Patrono C, and Page C eds), vol 210, pp 23-57, Springer, Berlin, Heidelberg.

Kereiakes DJ, Runyon JP, Broderick TM, and Shimshak TM (2000) IIb's are not IIb's. Am J Cardiol 85:23C-31C.

Khorana AA and Connolly GC (2009) Assessing risk of venous thromboembolism in the patient with cancer. J Clin Oncol 27:4839-4847.

Khorana AA and Fine RL (2004) Pancreatic cancer and thromboembolic disease. Lancet Oncol 5:655-663.

Khorana AA, Francis CW, Menzies KE, Wang JG, Hyrien O, Hathcock J, Mackman $\mathrm{N}$, and Taubman MB (2008) Plasma tissue factor may be predictive of venous thromboembolism in pancreatic cancer. J Thromb Haemost 6:1983-1985.

Kim S, Jin J, and Kunapuli SP (2006) Relative contribution of G-protein-coupled pathways to protease-activated receptor-mediated Akt phosphorylation in platelets. Blood 107:947-954.

King S, Short M, and Harmon C (2016) Glycoprotein IIb/IIIa inhibitors: the resurgence of tirofiban. Vascul Pharmacol 78:10-16.

Kosoglou T, Reyderman L, Tiessen RG, van Vliet AA, Fales RR, Keller R, Yang B, and Cutler DL (2012) Pharmacodynamics and pharmacokinetics of the novel PAR1 antagonist vorapaxar (formerly SCH 530348) in healthy subjects. Eur J Clin Pharmacol 68:249-258.

Koupenova M, Clancy L, Corkrey HA, and Freedman JE (2018) Circulating platelets as mediators of immunity, inflammation, and thrombosis. Circ Res 122:337-351.

Koupenova M, Mick E, Mikhalev E, Benjamin EJ, Tanriverdi K, and Freedman JE (2015) Sex differences in platelet Toll-like receptors and their association with cardiovascular risk factors. Arterioscler Thromb Vasc Biol 35:1030-1037.

Kovacs IB, Mayou SC, and Kirby JD (1991) Infusion of a stable prostacyclin analogue, iloprost, to patients with peripheral vascular disease: lack of antiplatelet effect but risk of thromboembolism. Am J Med 90:41-46.

Kraemer BF, Campbell RA, Schwertz H, Cody MJ, Franks Z, Tolley ND, Kahr WH, Lindemann S, Seizer P, Yost CC, et al. (2011) Novel anti-bacterial activities of $\beta$-defensin 1 in human platelets: suppression of pathogen growth and signaling of neutrophil extracellular trap formation. PLoS Pathog 7:e1002355.

Krämer HJ, Stevens J, Grimminger F, and Seeger W (1996) Fish oil fatty acids and human platelets: dose-dependent decrease in dienoic and increase in trienoic thromboxane generation. Biochem Pharmacol 52:1211-1217.

Krauel K, Pötschke C, Weber C, Kessler W, Fürll B, Ittermann T, Maier S, Ham merschmidt S, Bröker BM, and Greinacher A (2011) Platelet factor 4 binds to bacteria, [corrected] inducing antibodies cross-reacting with the major antigen in heparin-induced thrombocytopenia. Blood 117:1370-1378

Krauel K, Weber C, Brandt S, Zähringer U, Mamat U, Greinacher A and Hammerschmidt S (2012) Platelet factor 4 binding to lipid A of Gram-negative bacteria exposes PF4/heparin-like epitopes. Blood 120:3345-3352.

Kroeze WK, Sheffler DJ, and Roth BL (2003) G-protein-coupled receptors at a glance. J Cell Sci 116:4867-4869.

Kuter DJ (1996) The physiology of platelet production. Stem Cells 14 (Suppl 1): $88-101$.

Lafuente EM, van Puijenbroek AA, Krause M, Carman CV, Freeman GJ, Berezovskaya A, Constantine E, Springer TA, Gertler FB, and Boussiotis VA (2004) RIAM, an Ena/VASP and profilin ligand, interacts with Rap1-GTP and mediates Rap1-induced adhesion. Dev Cell 7:585-595.

Lagarde M, Bernoud-Hubac N, Calzada C, Véricel E, and Guichardant M (2013) Lipidomics of essential fatty acids and oxygenated metabolites. Mol Nutr Food Res 57:1347-1358.

Lefrancais E, Ortiz-Muñoz G, Caudrillier A, Mallavia B, Liu F, Sayah DM, Thornton EE, Headley MB, David T, Coughlin SR, et al. (2017) The lung is a site of platelet biogenesis and a reservoir for haematopoietic progenitors. Nature 544:105-109. 
Lei X, Reheman A, Hou Y, Zhou H, Wang Y, Marshall AH, Liang C, Dai X, Li BX, Vanhoorelbeke K, et al. (2014) Anfibatide, a novel GPIb complex antagonist, in hibits platelet adhesion and thrombus formation in vitro and in vivo in murine models of thrombosis. Thromb Haemost 111:279-289.

Levine GN, Bates ER, Blankenship JC, Bailey SR, Bittl JA, Cercek B, Chambers CE, Ellis SG, Guyton RA, Hollenberg SM, et al. (2011) 2011 ACCF/AHA/SCAI guideline for percutaneous coronary intervention: a report of the American College of Cardiology Foundation/American Heart Association Task Force on Practice Guidelines and the Society for Cardiovascular Angiography and Interventions [published correction appears in Circulation (2012) 125:e412]. Circulation 124:e574-e651.

Li TT, Fan ML, Hou SX, Li XY, Barry DM, Jin H, Luo SY, Kong F, Lau LF, Dai XR et al. (2015) A novel snake venom-derived GPIb antagonist, anfibatide, protects mice from acute experimental ischaemic stroke and reperfusion injury. $\mathrm{Br} J$ Pharmacol 172:3904-3916.

Li Z, Delaney MK, O'Brien KA, and Du X (2010) Signaling during platelet adhesion and activation. Arterioscler Thromb Vasc Biol 30:2341-2349.

Lincoff AM, Harrington RA, Califf RM, Hochman JS, Guerci AD, Ohman EM, Pepine CJ, Kopecky SL, Kleiman NS, Pacchiana CM, et al. (2000) Management of patients with acute coronary syndromes in the United States by platelet glycoprotein $\mathrm{IIb} / \mathrm{III}$ inhibition: insights from the platelet glycoprotein IIb/IIIa in unstable angina: receptor suppression using integrilin therapy (PURSUIT) trial. Circulation 102:1093-1100

Luci D, Jameson JB II, Yasgar A, Diaz G, Joshi N, Kantz A, Markham K, Perry S, Kuhn N, Yeung J, et al. (2010) Discovery of ML355, a Potent and Selective Inhibitor of Human 12-Lipoxygenase, Probe Reports from the NIH Molecular Libraries Program, Bethesda, MD

Lyman GH and Khorana AA (2009) Cancer, clots and consensus: new understanding of an old problem. J Clin Oncol 27:4821-4826.

Mackman N (2012) New insights into the mechanisms of venous thrombosis. J Clin Invest 122:2331-2336.

Manganiello VC, Murata T, Taira M, Belfrage P, and Degerman E (1995) Diversity in cyclic nucleotide phosphodiesterase isoenzyme families. Arch Biochem Biophys 322:1-13

Manly DA, Wang J, Glover SL, Kasthuri R, Liebman HA, Key NS, and Mackman N (2010) Increased microparticle tissue factor activity in cancer patients with venous thromboembolism. Thromb Res 125:511-512.

May F, Hagedorn I, Pleines I, Bender M, Vögtle T, Eble J, Elvers M, and Nieswandt B (2009) CLEC-2 is an essential platelet-activating receptor in hemostasis and thrombosis. Blood 114:3464-3472.

Mazharian A, Roger S, Berrou E, Adam F, Kauskot A, Nurden P, Jandrot-Perrus M, and Bryckaert M (2007) Protease-activating receptor-4 induces full platelet spreading on a fibrinogen matrix: involvement of ERK2 and p38 and Ca2+ mobilization. J Biol Chem 282:5478-5487.

McCoy KL, Gyoneva S, Vellano CP, Smrcka AV, Traynelis SF, and Hepler JR (2012) Protease-activated receptor 1 (PAR1) coupling to $G(q / 11)$ but not to $G(i / o$ ) or $G$ $(12 / 13)$ is mediated by discrete amino acids within the receptor second intracellular loop. Cell Signal 24:1351-1360.

Mezouar S, Darbousset R, Dignat-George F, Panicot-Dubois L, and Dubois C (2015) Inhibition of platelet activation prevents the P-selectin and integrin-dependent accumulation of cancer cell microparticles and reduces tumor growth and metastasis in vivo. Int $J$ Cancer 136:462-475.

Michael JV, Wurtzel JGT, Mao GF, Rao AK, Kolpakov MA, Sabri A, Hoffman NE, Rajan S, Tomar D, Madesh M, et al. (2017) Platelet microparticles infiltrating solid tumors transfer miRNAs that suppress tumor growth. Blood 130:567-580.

Mitrugno A, Williams D, Kerrigan SW, and Moran N (2014) A novel and essential role for Fc $\gamma$ RIIa in cancer cell-induced platelet activation. Blood 123:249-260.

Moers A, Nieswandt B, Massberg S, Wettschureck N, Grüner S, Konrad I, Schulte V, Aktas B, Gratacap MP, Simon MI, et al. (2003) G13 is an essential mediator of platelet activation in hemostasis and thrombosis. Nat Med 9:1418-1422.

Möhle R, Green D, Moore MA, Nachman RL, and Rafii S (1997) Constitutive production and thrombin-induced release of vascular endothelial growth factor by human megakaryocytes and platelets. Proc Natl Acad Sci USA 94:663-668.

Montoro-García S, Schindewolf M, Stanford S, Larsen OH, and Thiele T (2016) The role of platelets in venous thromboembolism. Semin Thromb Hemost 42:242-251.

Moore MG and Deschler DG (2007) Clopidogrel (Plavix) reduces the rate of thrombosis in the rat tuck model for microvenous anastomosis. Otolaryngol Head Neck Surg 136:573-576.

Moser M, Nieswandt B, Ussar S, Pozgajova M, and Fässler R (2008) Kindlin-3 is essential for integrin activation and platelet aggregation. Nat Med 14:325-330.

Murphy PM, Baggiolini M, Charo IF, Hébert CA, Horuk R, Matsushima K, Miller LH, Oppenheim JJ, and Power CA (2000) International union of pharmacology. XXII. Nomenclature for chemokine receptors. Pharmacol Rev 52:145-176.

Murugappa S and Kunapuli SP (2006) The role of ADP receptors in platelet function. Front Biosci 11:1977-1986.

Nieman MT (2008) Protease-activated receptor 4 uses anionic residues to interact with alpha-thrombin in the absence or presence of protease-activated receptor 1 Biochemistry 47:13279-13286.

Offermanns S (2001) In vivo functions of heterotrimeric G-proteins: studies in Galpha-deficient mice. Oncogene 20:1635-1642.

Offermanns S, Toombs CF, Hu YH, and Simon MI (1997) Defective platelet activation in G alpha(q)-deficient mice. Nature 389:183-186.

O'Gara PT, Kushner FG, Ascheim DD, Casey DE Jr, Chung MK, de Lemos JA Ettinger SM, Fang JC, Fesmire FM, Franklin BA, et al. American College of Cardiology Foundation; American Heart Association Task Force on Practice Guidelines; American College of Emergency Physicians; Society for Cardiovascular Angiography and Interventions (2013) 2013 ACCF/AHA guideline for the management of ST-elevation myocardial infarction: executive summary: a report of the American College of Cardiology Foundation/American Heart Association Task Force on Practice Guidelines: developed in collaboration with the American College of Emergency Physicians and Society for Cardiovascular Angiography and Interventions. Catheter Cardiovasc Interv 82:E1-E27.

Oki T, Kitaura J, Eto K, Lu Y, Maeda-Yamamoto M, Inagaki N, Nagai H, Yamanish $\mathrm{Y}$, Nakajima H, Kumagai H, et al. (2006) Integrin alphaIIbbeta3 induces the adhesion and activation of mast cells through interaction with fibrinogen [published correction appears in $J$ Immunol (2006) 176:3841]. J Immunol 176:52-60.

Onlamoon N, Noisakran S, Hsiao HM, Duncan A, Villinger F, Ansari AA, and Perng GC (2010) Dengue virus-induced hemorrhage in a nonhuman primate model. Blood 115:1823-1834.

O'Shea JC, Hafley GE, Greenberg S, Hasselblad V, Lorenz TJ, Kitt MM, Strony J, and Tcheng JE; ESPRIT Investigators (Enhanced Suppression of the Platelet IIb/IIIa Receptor with Integrilin Therapy Trial) (2001) Platelet glycoprotein IIb/IIIa integrin blockade with eptifibatide in coronary stent intervention: the ESPRIT trial: a randomized controlled trial. JAMA 285:2468-2473.

O'Shea JC and Tcheng JE (2001) Eptifibatide in percutaneous coronary intervention: the ESPRIT trial results. Curr Interv Cardiol Rep 3:62-68.

Ossovskaya VS and Bunnett NW (2004) Protease-activated receptors: contribution to physiology and disease. Physiol Rev 84:579-621.

Ouseph MM, Huang Y, Banerjee M, Joshi S, MacDonald L, Zhong Y, Liu H, Li X, Xiang B, Zhang G, et al. (2015) Autophagy is induced upon platelet activation and is essential for hemostasis and thrombosis [published correction appears in Blood (2015) 126:2072]. Blood 126:1224-1233.

Pampolina C and McNicol A (2005) Streptococcus sanguis-induced platelet activation involves two waves of tyrosine phosphorylation mediated by FcgammaRIIA and alphaIIbbeta3. Thromb Haemost 93:932-939.

Pasquet JM, Gross B, Quek L, Asazuma N, Zhang W, Sommers CL, Schweighoffer E, Tybulewicz V, Judd B, Lee JR, et al. (1999) LAT is required for tyrosine phosphorylation of phospholipase Cgamma2 and platelet activation by the collagen receptor GPVI. Mol Cell Biol 19:8326-8334.

Patrono C, García Rodríguez LA, Landolfi R, and Baigent C (2005) Low-dose aspirin for the prevention of atherothrombosis. N Engl J Med 353:2373-2383.

Pearce AC, Senis YA, Billadeau DD, Turner M, Watson SP, and Vigorito E (2004) Vav1 and vav3 have critical but redundant roles in mediating platelet activation by collagen. J Biol Chem 279:53955-53962.

Pearce AC, Wilde JI, Doody GM, Best D, Inoue O, Vigorito E, Tybulewicz VL, Turner M, and Watson SP (2002) Vav1, but not Vav2, contributes to platelet aggregation by $\mathrm{CRP}$ and thrombin, but neither is required for regulation of phospholipase $\mathrm{C}$ Blood 100:3561-3569.

Prasad KS, Andre P, He M, Bao M, Manganello J, and Phillips DR (2003) Soluble CD40 ligand induces beta3 integrin tyrosine phosphorylation and triggers platelet activation by outside-in signaling. Proc Natl Acad Sci USA 100: $12367-12371$

Prohászka Z (2008) Haemolytic uremic syndrome and thrombotic thrombocytopenic purpura: classification based on molecular etiology and review of recent developments in diagnostics. Orv Hetil 149:1251-1261.

Prota AE, Campbell JA, Schelling P, Forrest JC, Watson MJ, Peters TR, AurrandLions M, Imhof BA, Dermody TS, and Stehle T (2003) Crystal structure of human junctional adhesion molecule 1: implications for reovirus binding. Proc Natl Acad Sci USA 100:5366-5371.

Quek LS, Bolen J, and Watson SP (1998) A role for Bruton's tyrosine kinase (Btk) in platelet activation by collagen. Curr Biol 8:1137-1140.

Raychowdhury MK, Yukawa M, Collins LJ, McGrail SH, Kent KC, and Ware JA (1994) Alternative splicing produces a divergent cytoplasmic tail in the human endothelial thromboxane A2 receptor. J Biol Chem 269:19256-19261.

Ricciotti E and FitzGerald GA (2011) Prostaglandins and inflammation. Arterioscler Thromb Vasc Biol 31:986-1000.

Rouzer CA and Marnett LJ (2009) Cyclooxygenases: structural and functional insights. J Lipid Res 50 (Suppl):S29-S34.

Savi P, Bernat A, Dumas A, Ait-Chek L, and Herbert JM (1994) Effect of aspirin and clopidogrel on platelet-dependent tissue factor expression in endothelial cells. Thromb Res 73:117-124.

Savi P, Bernat A, Lalé A, Roque C, Zamboni G, and Herbert JM (2000) Effect of aspirin on platelet desaggregation induced by SR121566, a potent GP-IIb/IIIa antagonist. Platelets 11:43-48.

Schneider DJ, Herrmann HC, Lakkis N, Aguirre F, Lo MW, Yin KC, Aggarwal A Kabbani SS, and DiBattiste PM (2003) Increased concentrations of tirofiban in blood and their correlation with inhibition of platelet aggregation after greater bolus doses of tirofiban. Am J Cardiol 91:334-336.

Seeley S, Covic L, Jacques SL, Sudmeier J, Baleja JD, and Kuliopulos A (2003) Structural basis for thrombin activation of a protease-activated receptor: inhibition of intramolecular liganding. Chem Biol 10:1033-1041.

Semple JW and Freedman J (2010) Platelets and innate immunity. Cell Mol Life Sci 67:499-511.

Sergeant S, Rahbar E, and Chilton FH (2016) Gamma-linolenic acid, dihommo-gamma linolenic, eicosanoids and inflammatory processes. Eur J Pharmacol 785:77-86.

Shattil SJ, Kim C, and Ginsberg MH (2010) The final steps of integrin activation: the end game. Nat Rev Mol Cell Biol 11:288-300.

Shiraki R, Inoue N, Kawasaki S, Takei A, Kadotani M, Ohnishi Y, Ejiri J, Kobayashi S, Hirata K, Kawashima S, et al. (2004) Expression of Toll-like receptors on human platelets. Thromb Res 113:379-385.

Sible AM and Nawarskas JJ (2017) Cangrelor: a new route for P2Y12 inhibition. Cardiol Rev 25:133-139.

Soulet C, Hechler B, Gratacap MP, Plantavid M, Offermanns S, Gachet C, and Payrastre B (2005) A differential role of the platelet ADP receptors P2Y1 and P2Y12 in Rac activation. J Thromb Haemost 3:2296-2306.

Ståhl AL, Svensson M, Mörgelin M, Svanborg C, Tarr PI, Mooney JC, Watkins SL, Johnson R, and Karpman D (2006) Lipopolysaccharide from enterohemorrhagic Escherichia coli binds to platelets through TLR4 and CD62 and is detected on circulating platelets in patients with hemolytic uremic syndrome. Blood 108: 167-176. 
Stalker TJ, Newman DK, Ma P, Wannemacher KM, and Brass LF (2012) Platelet signaling. Handb Exp Pharmacol 210:59-85.

Stalker TJ, Traxler EA, Wu J, Wannemacher KM, Cermignano SL, Voronov R, Diamond SL, and Brass LF (2013) Hierarchical organization in the hemostatic response and its relationship to the platelet-signaling network. Blood 121:1875-1885.

Stegner D, Haining EJ, and Nieswandt B (2014) Targeting glycoprotein VI and the immunoreceptor tyrosine-based activation motif signaling pathway. Arterioscler Thromb Vasc Biol 34:1615-1620.

Storey RF, Oldroyd KG, and Wilcox RG (2001) Open multicentre study of the P2T receptor antagonist AR-C69931MX assessing safety, tolerability and activity in patients with acute coronary syndromes. Thromb Haemost 85:401-407.

Sugimoto Y and Narumiya S (2007) Prostaglandin E receptors. J Biol Chem 282 11613-11617.

Suh JW, Lee SP, Park KW, Lee HY, Kang HJ, Koo BK, Cho YS, Youn TJ, Chae IH, Choi DJ, et al. (2011) Multicenter randomized trial evaluating the efficacy of cilostazol on ischemic vascular complications after drug-eluting stent implantation for coronary heart disease: results of the CILON-T (influence of CILostazol-based triple antiplatelet therapy $\mathrm{ON}$ ischemic complication after drug-eluting stenT implantation) trial. J Am Coll Cardiol 57:280-289.

Sullam PM, Jarvis GA, and Valone FH (1988) Role of immunoglobulin G in platelet aggregation by viridans group streptococci. Infect Immun 56:2907-2911.

Sun L, Xu YW, Han J, Liang H, Wang N, and Cheng Y (2015) 12/15-Lipoxygenase metabolites of arachidonic acid activate PPAR $\gamma$ : a possible neuroprotective effect in ischemic brain. J Lipid Res 56:502-514.

Suzuki-Inoue K, Inoue O, Ding G, Nishimura S, Hokamura K, Eto K, Kashiwagi H Tomiyama Y, Yatomi Y, Umemura K, et al. (2010) Essential in vivo roles of the C-type lectin receptor CLEC-2: embryonic/neonatal lethality of CLEC-2-deficient mice by blood/lymphatic misconnections and impaired thrombus formation of CLEC-2-deficient platelets. J Biol Chem 285:24494-24507.

Tadokoro S, Shattil SJ, Eto K, Tai V, Liddington RC, de Pereda JM, Ginsberg MH, and Calderwood DA (2003) Talin binding to integrin beta tails: a final common step in integrin activation. Science 302:103-106.

Takagi S, Sato S, Oh-hara T, Takami M, Koike S, Mishima Y, Hatake K, and Fujita N (2013) Platelets promote tumor growth and metastasis via direct interaction between Aggrus/podoplanin and CLEC-2. PLoS One 8:e73609.

Takenaga M, Hirai A, Terano T, Tamura Y, Kitagawa H, and Yoshida S (1986) Comparison of the in vitro effect of eicosapentaenoic acid (EPA)-derived lipoxygenase metabolites on human platelet function with those of arachidonic acid. Thromb Res 41:373-384.

Tello-Montoliu A, Tomasello SD, Ueno M, and Angiolillo DJ (2011) Antiplatelet therapy: thrombin receptor antagonists. Br J Clin Pharmacol 72:658-671.

Teng R and Butler K (2013) Safety, tolerability, pharmacokinetics and pharmacodynamics of high single-ascending doses of ticagrelor in healthy volunteers. Int $J$ Clin Pharmacol Ther 51:795-806.

Tesselaar ME, Romijn FP, van der Linden IK, Bertina RM, and Osanto S (2009) Microparticle-associated tissue factor activity in cancer patients with and without thrombosis. J Thromb Haemost 7:1421-1423.

Tomaiuolo M, Brass LF, and Stalker TJ (2017) Regulation of platelet activation and coagulation and its role in vascular injury and arterial thrombosis. Interv Cardiol Clin 6:1-12.

Topol EJ (1999) New platelet glycoprotein IIb/IIIa inhibitor trials in percutaneous coronary intervention. J Invasive Cardiol 11 (Suppl C):3C-6C.

Topol EJ, Moliterno DJ, Herrmann HC, Powers ER, Grines CL, Cohen DJ, Cohen EA, Bertrand M, Neumann FJ, Stone GW, et al.; TARGET Investigators: Do Tirofiban and ReoPro Give Similar Efficacy Trial (2001) Comparison of two platelet glycoprotein IIb/IIIa inhibitors, tirofiban and abciximab, for the prevention of ischemic events with percutaneous coronary revascularization. $N$ Engl J Med 344:1888-1894.

Tourdot BE, Adili R, Isingizwe ZR, Ebrahem M, Freedman JC, Holman TR, and Holinstat M (2017) 12-HETrE inhibits platelet reactivity and thrombosis in part through the prostacyclin receptor. Blood Adv 1:1124-1131.

Umemura K, Ikeda Y, and Kondo K (2016) Pharmacokinetics and pharmacodynamics of prasugrel in healthy Japanese subjects. Drug Metab Pharmacokinet 31:285-291.

Umemura K and Iwaki T (2016) The pharmacokinetics and pharmacodynamics of prasugrel and clopidogrel in healthy Japanese volunteers. Clin Pharmacol Drug Dev 5:480-487.

Ungerer M, Li Z, Baumgartner C, Goebel S, Vogelmann J, Holthoff HP, Gawaz M, and Münch G (2013) The GPVI-Fc fusion protein Revacept reduces thrombus formation and improves vascular dysfunction in atherosclerosis without any impact on bleeding times. PLoS One 8:e71193.

Ungerer M, Rosport K, Bültmann A, Piechatzek R, Uhland K, Schlieper P, Gawaz M, and Münch G (2011) Novel antiplatelet drug revacept (dimeric glycoprotein VI-Fc) specifically and efficiently inhibited collagen-induced platelet aggregation without affecting general hemostasis in humans. Circulation 123:1891-1899.

Valgimigli M, Campo G, de Cesare N, Vranckx P, Hamon M, Angiolillo DJ, Sabatè M, Ferrari F, Furgieri A, Tumscitz C, et al. (2008) Tailoring treatment with tirofiban in patients showing resistance to aspirin and/or resistance to clopidogrel (3T/2R): rationale for the study and protocol design. Cardiovasc Drugs Ther 22:313-320.

Varon D, Hayon Y, Dashevsky O, and Shai E (2012) Involvement of platelet derived microparticles in tumor metastasis and tissue regeneration. Thromb Res 130 (Suppl 1):S98-S99.

von Hundelshausen P and Weber C (2007) Platelets as immune cells: bridging inflammation and cardiovascular disease. Circ Res 100:27-40.

Vorchheimer DA, Badimon JJ, and Fuster V (1999) Platelet glycoprotein IIb/IIIa receptor antagonists in cardiovascular disease. JAMA 281:1407-1414.

Voss B, McLaughlin JN, Holinstat M, Zent R, and Hamm HE (2007) PAR1, but not PAR4, activates human platelets through a Gi/o/phosphoinositide-3 kinase signaling axis. Mol Pharmacol 71:1399-1406.
Wagner CL, Mascelli MA, Neblock DS, Weisman HF, Coller BS, and Jordan RE (1996) Analysis of GPIIb/IIIa receptor number by quantification of 7E3 binding to human platelets. Blood 88:907-914.

Wallentin L, Becker RC, Budaj A, Cannon CP, Emanuelsson H, Held C, Horrow J, Husted S, James S, Katus H, et al.; PLATO Investigators (2009) Ticagrelor versus clopidogrel in patients with acute coronary syndromes. $N$ Engl $J$ Med 361: 1045-1057.

Wang YX, Vincelette J, da Cunha V, Martin-McNulty B, Mallari C, Fitch RM, Alexander S, Islam I, Buckman BO, Yuan S, et al. (2007) A novel P2Y(12) adenosine diphosphate receptor antagonist that inhibits platelet aggregation and thrombus formation in rat and dog models. Thromb Haemost 97:847-855.

Welsh JD, Muthard RW, Stalker TJ, Taliaferro JP, Diamond SL, and Brass LF (2016) A systems approach to hemostasis: 4. How hemostatic thrombi limit the loss of plasma-borne molecules from the microvasculature. Blood 127: 1598-1605.

Welsh JD, Stalker TJ, Voronov R, Muthard RW, Tomaiuolo M, Diamond SL, and Brass LF (2014) A systems approach to hemostasis: 1. The interdependence of thrombus architecture and agonist movements in the gaps between platelets. Blood 124:1808-1815.

Wettschureck N, Moers A, and Offermanns S (2004) Mouse models to study G-protein-mediated signaling. Pharmacol Ther 101:75-89.

Weyrich AS and Zimmerman GA (2013) Platelets in lung biology. Annu Rev Physiol 75:569-591.

Wilson SJ, Ismat FA, Wang Z, Cerra M, Narayan H, Raftis J, Gray TJ, Connell S, Garonzik S, Ma X, et al. (2018) PAR4 (protease-activated receptor 4) antagonism with BMS-986120 inhibits human ex vivo thrombus formation. Arterioscler Thromb Vasc Biol 38:448-456.

Wiviott SD, Braunwald E, McCabe CH, Montalescot G, Ruzyllo W, Gottlieb S, Neumann FJ, Ardissino D, De Servi S, Murphy SA, et al.; TRITON-TIMI 38 Investigators (2007) Prasugrel versus clopidogrel in patients with acute coronary syndromes. N Engl J Med 357:2001-2015.

Wong PC, Seiffert D, Bird JE, Watson CA, Bostwick JS, Giancarli M, Allegretto N, Hua J, Harden D, Guay J, et al. (2017) Blockade of protease-activated receptor-4 (PAR4) provides robust antithrombotic activity with low bleeding. Sci Transl Med 9:1-11.

Wong SKF, Parker EM, and Ross EM (1990) Chimeric muscarinic cholinergic: betaadrenergic receptors that activate $\mathrm{Gs}$ in response to muscarinic agonists. $J$ Biol Chem 265:6219-6224.

Woulfe DS (2005) Platelet G protein-coupled receptors in hemostasis and thrombosis. $J$ Thromb Haemost 3:2193-2200.

Xu WF, Andersen H, Whitmore TE, Presnell SR, Yee DP, Ching A, Gilbert T, Davie EW, and Foster DC (1998) Cloning and characterization of human proteaseactivated receptor 4. Proc Natl Acad Sci USA 95:6642-6646.

Yamamoto H, Takahashi K, Watanabe H, Yoshikawa Y, Shirakawa R, Higashi T, Kawato M, Ikeda T, Tabuchi A, Morimoto T, et al. (2008) Evaluation of the antiplatelet effects of cilostazol, a phosphodiesterase 3 inhibitor, by VASP phosphorylation and platelet aggregation. Circ J 72:1844-1851.

Yamamoto S (1992) Mammalian lipoxygenases: molecular structures and functions. Biochim Biophys Acta 1128:117-131.

Yeaman MR (2010) Platelets in defense against bacterial pathogens. Cell Mol Life Sci 67:525-544.

Yeung J, Apopa PL, Vesci J, Kenyon V, Rai G, Jadhav A, Simeonov A, Holman TR, Maloney DJ, Boutaud O, et al. (2012) Protein kinase C regulation of 12-lipoxygenase-mediated human platelet activation. Mol Pharmacol 81:420-430.

Yeung J, Hawley M, and Holinstat M (2017) The expansive role of oxylipins on platelet biology. J Mol Med (Berl) 95:575-588.

Yeung $J$ and Holinstat M (2012) Newer agents in antiplatelet therapy: a review. $J$ Blood Med 3:33-42.

Yeung J, Tourdot BE, Adili R, Green AR, Freedman CJ, Fernandez-Perez P, Yu J, Holman TR, and Holinstat M (2016) 12(S)-HETrE, a 12-lipoxygenase oxylipin of dihomo- $\gamma$-linolenic acid, inhibits thrombosis via $\mathrm{G} \alpha \mathrm{s}$ signaling in platelets. Arterioscler Thromb Vasc Biol 36:2068-2077.

Yeung J, Tourdot BE, Fernandez-Perez P, Vesci J, Ren J, Smyrniotis CJ, Luci DK, Jadhav A, Simeonov A, Maloney DJ, et al. (2014) Platelet 12-LOX is essential for Fc $\gamma$ RIIa-mediated platelet activation. Blood 124:2271-2279.

Yoo HD, Cho HY, and Lee YB (2010) Population pharmacokinetic analysis of cilostazol in healthy subjects with genetic polymorphisms of CYP3A5, CYP2C19 and ABCB1. Br J Clin Pharmacol 69:27-37.

Yoo HD, Park SA, Cho HY, and Lee YB (2009) Influence of CYP3A and CYP2C19 genetic polymorphisms on the pharmacokinetics of cilostazol in healthy subjects. Clin Pharmacol Ther 86:281-284

Zhang G, Han J, Welch EJ, Ye RD, Voyno-Yasenetskaya TA, Malik AB, Du X, and Li $\mathrm{Z}$ (2009) Lipopolysaccharide stimulates platelet secretion and potentiates platelet aggregation via TLR4/MyD88 and the cGMP-dependent protein kinase pathway. $J$ Immunol 182:7997-8004.

Zhao P, Metcalf M, and Bunnett NW (2014) Biased signaling of protease-activated receptors. Front Endocrinol (Lausanne) 5:67.

Zheng L, Mao Y, Abdelgawwad MS, Kocher NK, Li M, Dai X, Li B, and Zheng XI (2016) Therapeutic efficacy of the platelet glycoprotein Ib antagonist anfibatide in murine models of thrombotic thrombocytopenic purpura. Blood Adv 1:75-83.

Zucchella M, Dezza L, Pacchiarini L, Meloni F, Tacconi F, Bonomi E, Grignani G, and Notario A (1989) Human tumor cells cultured "in vitro" activate platelet function by producing ADP or thrombin. Haematologica 74:541-545.

Zwicker JI, Liebman HA, Neuberg D, Lacroix R, Bauer KA, Furie BC, and Furie B (2009) Tumor-derived tissue factor-bearing microparticles are associated with venous thromboembolic events in malignancy. Clin Cancer Res 15: 6830-6840. 